\title{
Investigation Structure and Properties of Wire From The Alloy of Al-rem System Obtained With The Application of Casting in The Electromagnetic Mold, Combined Rolling-Extruding and Drawing
}

Sergey Borisovich Sidelnikov

Siberian Federal University

Denis Sergeevich Voroshilov ( $\sim$ d.s.voroshilov@gmail.com )

Siberian Federal University https://orcid.org/0000-0002-1406-3665

Mikhail Mikhaylovich Motkov

Siberian Federal University

Viktor Nikolaevich Timofeev

Siberian Federal University

Igor Lazarevich Konstantinov

Siberian Federal University

Nikolay Nikolaevich Dovzhenko

Siberian Federal University

Ekaterina Sergeevna Lopatina

Siberian Federal University

Vadim Mikhaylovich Bespalov

Siberian Federal University

Ruslan Evgenyevich Sokolov

Siberian Federal University

Yulbarskhon Nabievich Mansurov

Tashkent State Transport University

Marina Vladimirovna Voroshilova

Siberian Federal University

\section{Research Article}

Keywords: Aluminum alloys, Rare earth metals, Wire, Physical and mechanical properties, Metal structure, Casting, Electromagnetic mold, Combined rolling-extruding, Drawing

Posted Date: March 1st, 2021 
DOI: https://doi.org/10.21203/rs.3.rs-250093/v1

License: (c) (1) This work is licensed under a Creative Commons Attribution 4.0 International License. Read Full License

Version of Record: A version of this preprint was published at The International Journal of Advanced Manufacturing Technology on April 12th, 2021. See the published version at https://doi.org/10.1007/s00170-021-07054-x. 


\title{
INVESTIGATION STRUCTURE AND PROPERTIES OF WIRE FROM THE ALLOY OF Al-REM SYSTEM OBTAINED WITH THE APPLICATION OF CASTING IN THE ELECTROMAGNETIC MOLD, COMBINED ROLLING-EXTRUDING AND DRAWING
}

Sergey Borisovich Sidelnikov ${ }^{1}$, Denis Sergeevich Voroshilov ${ }^{1 *}$, Mikhail Mikhaylovich Motkov ${ }^{1,2}$, Viktor Nikolaevich Timofeev $^{1,2}$, Igor Lazarevich Konstantinov ${ }^{1}$, Nikolay Nikolaevich Dovzhenko ${ }^{1}$, Ekaterina Sergeevna Lopatina ${ }^{1}$, Vadim Mikhaylovich Bespalov ${ }^{1}$, Ruslan Evgenyevich Sokolov ${ }^{1}$, Yulbarskhon Nabievich Mansurov ${ }^{3}$, Marina Vladimirovna Voroshilova ${ }^{1}$

${ }^{1}$ Siberian federal university, Krasnoyarsk, 660025, Krasnoyarsk Region, Russian Federation

${ }^{2}$ LLC «Research and Production Center of Magnetic Hydro Hydrodynamics», Krasnoyarsk, 660074, Krasnoyarsk Region, Russian Federation

${ }^{3}$ Institute of General and Inorganic Chemistry of the Academy of Sciences of the Republic of Uzbekistan, Tashkent State Transport University, Tashkent, 100000, The Republic of Uzbekistan

*E-mail: d.s.voroshilov@gmail.com

\begin{abstract}
The paper presents the results of studies of the structure and properties of a wire with a diameter of $0.5 \mathrm{~mm}$ from an alloy of the Al-REM system with a rare-earth metal content of 7-9\%. Wire obtained as a result of the implementation of the technology of its manufacture using the methods of casting into an electromagnetic mold (EMM), continuous extruding and drawing.

The rheological properties of the metal of continuously cast round billets from the experimental alloy obtained using an electromagnetic mold are determined. The modeling and analytical assessment of the possibility of carrying out the process of combined rolling-extruding (CRE) of such billets in a closed boxtype roll groove of a continuous extruding unit are carried out. The features of metal shaping have been studied. The temperature-speed and technological parameters was found at which the CRE process can be carried out in a stable mode of operation. Data have been obtained for the forces acting on the die and rolls and the moments on the rolls during rolling-extruding.

The results of experimental studies of the process of obtaining longish deformed semi-finished products from an experimental alloy on the laboratory unit CRE-200 and the pilot plant unit CRE-400 are presented. The structure of the metal has been studied; data on the ultimate tensile strength, yield strength, relative elongation, and electrical resistivity of hot-extruded rods and wires in cold-worked and annealed states have been obtained.

It was found that the proposed processing modes make it possible to obtain by the method of combined rolling-extruding rods with a diameter of $9 \mathrm{~mm}$ in industrial conditions from longish billets with a diameter of $18 \mathrm{~mm}$, cast by means of EMM. Wire in a cold-worked and annealed state with a diameter of 0.5 obtained by drawing from the rods with a diameter of $9 \mathrm{~mm}$ from an experimental alloy of the Al-REM system containing 7-9 rare earth metals with the required physical and mechanical properties.
\end{abstract}

Keywords: Aluminum alloys, Rare earth metals, Wire, Physical and mechanical properties, Metal structure, Casting, Electromagnetic mold, Combined rolling-extruding, Drawing.

\section{Introduction}

Deformed longish semi-finished products in the form of rods, wire rods and wires made of aluminum alloys are widely used for the manufacture of electrical products [1-5]. High performance properties in combination with low specific mass and high electrical conductivity make it possible to use cable products in power lines, aviation and space technology. In the manufacture of electrical conductors for aircraft operating at elevated temperatures (up to $250{ }^{\circ} \mathrm{C}$ ) high-alloyed aluminum alloys with rare earth metals (REM) are most used, which have the necessary complex of mechanical, electrical properties and thermal resistance. One of these alloys is an aluminum alloy of the Al-REM system with a rare-earth metal content of 7-9\%, from which a wire with a diameter of 1.0-1.2 mm was produced using a multistage pellet technology [6, 7]. That technology including 17 technological stages. Since these alloys have a limited resource of plastic properties the use of traditional technologies for obtaining deformed semi-finished products from them (for example, 
discrete extrusion on horizontal hydraulic extruders) has not found wide application in industry. In addition, this led to a high cost of semi-finished products due to the high labor intensity and high energy consumption for their production.

Recently, a need has arisen for a wire of small diameters of 0.1-0.5 mm made of these alloys, which has the following complex of physical and mechanical properties: the ultimate tensile strength under tension should be within the range $R_{m}=180-200 \mathrm{MPa}$; ultimate tensile strength at a temperature of $250{ }^{\circ} \mathrm{C}$ in the range of $R_{m}=100-120 \mathrm{MPa}$; the elongation to failure is $A=8-14 \%$; electrical resistance $\rho=0.03000-0.03200 \mathrm{Ohm} \cdot \mathrm{m} / \mathrm{mm}^{2}$ (according to TS 1-809-1038-2018 [8]). Since the resource of plastic and strength properties of alloys of the Al-REM system is limited, it is required to develop a technology for manufacturing such a wire, obtained on drawing machines for fine and finest drawing, having the required set of properties.

Despite the fact that the study of the structure, properties and processing technologies of the alloys Al-REM system are devoted to the works of many domestic and foreign scientists [1, 9-50] the task of creating an energy-efficient technology for producing wires with a diameter of 0.1-0.5 $\mathrm{mm}$ from these alloys still not resolved. Work [1] covers laboratory and industrial efforts of applying cerium for a purpose of developing aluminum alloys with superior properties. The binary Al-Ce, ternary Al-Ce-X and higher-order phase systems are reviewed with a focus on the aluminum-rich sections. In work [9] technologically important eutectic transformation in $\mathrm{Al}-\mathrm{Ce}$ binary alloys, containing from 5 to $20 \mathrm{wt} \% \mathrm{Ce}$ and ranging from hypo- to hypereutectic compositions, was examined along with the microstructure and properties of its solidified product. The advantages of REM in aluminum alloys are described in detail in work [1, 9, 10, 15-19].

The influence of REM in aluminum alloys on mechanical properties is considered in the works [20, 26-32, 34, 37-40, 43-45, 47, 48]. The influence of REM in aluminum alloys on electrical conductivity is considered in the works [20, 25, 31, 33, 34, 40, 42-45, 48]. The Ce content from 0.05 to $0.16 \mathrm{wt} . \%$ in the aluminum alloy is beneficial for increasing the electrical conductivity and tensile strength, since $\mathrm{Ce}$ reduces the solubility of solid impurity elements ( $\mathrm{Fe}, \mathrm{Si}$ ) in the aluminum matrix.

The use of high-alloyed alloys of the Al-REM system also provides significant advantages if it is required to increase the strength properties of the alloy, although this leads to a decrease in electrical conductivity [43-48].

At the same time, recently, in order to obtain longish semi-finished products from aluminum alloys technologies have been developed for continuous casting of ingots of small cross-section into an electromagnetic mold (EMM) and their subsequent deformation on installations for continuous extrusion Conform [61, 62] or combined rolling-extruding (CRE) [60, 63-65] and drawing [4, 22$24,50-65]$. The use of such technologies can lead to the solution of these issues and the production of small-diameter wire with the required set of operational properties. Therefore, an urgent scientific and technical problem is the development of new technologies of combined processing for obtaining long semi-finished products from high-alloyed alloys of the Al-REM system.

Therefore, the purpose of the research was the development of technical and technological solutions for the production of wire with a diameter of 0.1-0.5 $\mathrm{mm}$ from an experimental aluminum alloy with an REM content of 7-9\% with the required level of physical, mechanical and operational properties using continuous casting methods in electromagnetic mold, extruding and drawing.

To achieve this goal, the following tasks were set and solved:

- determination of rheological properties for cast billets from a test alloy and computer simulation of the process of CRE of a rod using a round billet from this alloy;

- development of a methodology for determining the feasibility and power parameters of the CRE process in a box gauge of a billet with a circular cross-section from an experimental alloy obtained in EMM;

- carrying out experimental studies of deformation force parameters for continuous extruding of rods from an experimental alloy on CRE units; 
- development of wire drawing routes and annealing modes when using rods manufactured on CRE units;

- carrying out studies of the structure and properties of rods and wires from the experimental alloy obtained using the methods of continuous casting into EMM, continuous extruding and drawing, founding the patterns of their change from the parameters of deformation processing.

- development of new technologies for combined processing and devices for its implementation in order to obtain wire from an experimental alloy with a given level of physical and mechanical properties and approbation of research results in industrial conditions.

\section{Materials and method of carrying out research}

For the production of high-quality cast billets with a small cross-section, the continuous casting method using EMM has been increasingly used. At the same time, due to high cooling rates and the absence of metal contact with the walls of the mold, it is possible to obtain billets of small diameters $(5-18 \mathrm{~mm})$ with a fine-grained structure and increased plastic properties $[6,11-14,51$ 55]. The ingot obtained in the EMM has a dendritic parameter 100 times less than when casting into a slip mold and is comparable to the structure of granules (Table 1). In addition, dendritic segregation and non-metallic inclusions are practically absent in these ingots, which is not achieved even with the use of granular technology. This makes it possible to use continuously cast billets of small cross-section for a high-performance continuous process of CRE and to obtain longish extruded products from low-plasticity aluminum alloys for subsequent wire drawing.

Table 1 - Comparison of parameters of different casting methods

\begin{tabular}{|c|c|c|c|}
\hline Casting method & Product type & Cooling rate, K/s & Structure \\
\hline Slip casting mold & Ingots & $5 \times 10^{1}$ & \\
& & & \\
Cooling melt \\
droplets in water
\end{tabular}

To determine the rheological properties of such continuously cast billets with a diameter of $12 \mathrm{~mm}$ from a test alloy (Table 2) the method of hot twisting of samples was used [66, 67] in a wide range of temperature, rate, and degree of deformation (Fig. 1).

$\mu$

Table 2 - Chemical composition of the test alloy system Al-REM [18-20]

\begin{tabular}{|c|c|c|c|c|c|c|}
\hline \multicolumn{7}{|c|}{ Component content in the alloy, wt. \% } \\
\hline $\mathrm{Ce}$ & $\mathrm{La}$ & $\mathrm{Pr}$ & $\mathrm{Fe}$ & $\mathrm{Si}$ & $\mathrm{Sm}$ & $\mathrm{Al}$ \\
\hline $4.4-4.7$ & $2.3-2.5$ & 0.1 & 0.2 & 0.1 & 0.1 & $\mathrm{Basis}$ \\
\hline
\end{tabular}




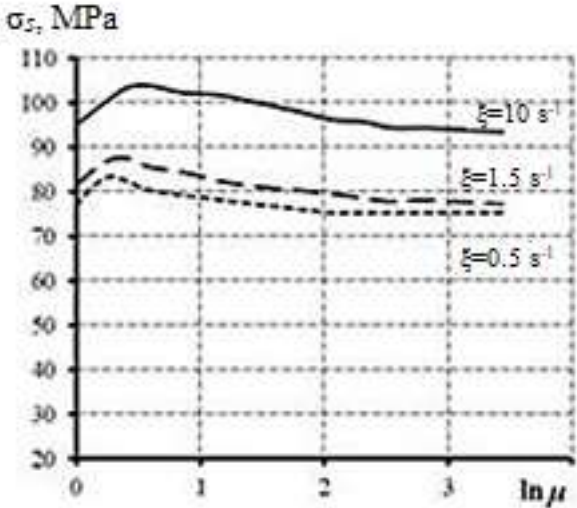

$a$

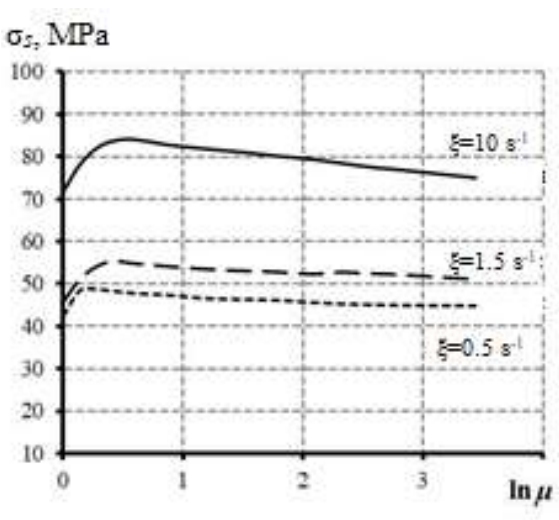

$b$

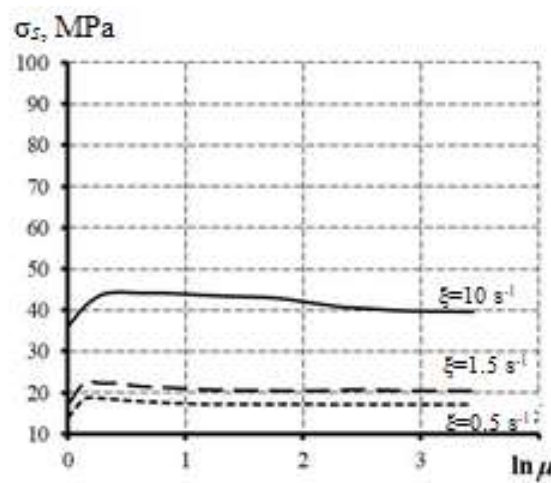

$c$

Fig. 1. Dependence of the resistance to deformation $\sigma_{s}$ of the experimental alloy on the degree of deformation $\ln \mu$ at different rates of deformation $\xi$ and heating temperatures:

$$
a-320{ }^{\circ} \mathrm{C} ; b-400{ }^{\circ} \mathrm{C} ; c-550{ }^{\circ} \mathrm{C}
$$

To determine the rheological properties according to the method developed at the Department of Metal Forming of School of Non-ferrous Metals and Materials Science of the Siberian Federal University (SibFU) torsion was carried out on the existing unit in different modes in a wide range of temperature, rate and degree of deformation (Fig. 1). The analysis of the obtained dependences showed that the shape of the hardening curves for the 01417 alloy has a typical character, as for most other aluminum alloys. With an increase in the test temperature the hardening rate increases. The obtained data on the rheological properties were used for computer modeling of the CRE process in a box gauge of a round billet. The diagram of the process is shown in Fig. 2, using the laboratory CRE-200 unit (Table 3).

Table 3 - CRE process parameters for different units

\begin{tabular}{|l|c|c|}
\hline \multicolumn{1}{|c|}{ Parameters } & $\begin{array}{c}\text { CRE-200 } \\
\text { (laboratory unit) }\end{array}$ & $\begin{array}{c}\text { CRE-400 } \\
\text { (industrial unit) }\end{array}$ \\
\hline Roll diameter with the protrusion $D_{1}, \mathrm{~mm}$ & 214 & 385 \\
\hline Roll diameter with the groove $D_{2}, \mathrm{~mm}$ & 167 & 385 \\
\hline Roll rotation frequency $\omega, \mathrm{rpm}$ & $4 ; 8$ & $4 ; 8$ \\
\hline The size of the gap between the rolls $\delta, \mathrm{mm}$ & 2 & 2 \\
\hline Roll ridge height with protrusion $h_{p e}, \mathrm{~mm}$ & 7 & 8 \\
\hline Diameter of the billet $d_{0}, \mathrm{~mm}$ & 12 & $12 ; 18$ \\
\hline The dimensions of the caliber in the smallest section $h \times b, \mathrm{~mm}$ & $7 \times 15$ & $7 \times 15 ; 10 \times 21$ \\
\hline The degree of deformation in height during rolling $\varepsilon, \%$ & 50 & 50 \\
\hline Die surface height $h_{d}, \mathrm{~mm}$ & 20 & $20 ; 26$ \\
\hline Die calibrating hole diameter $d_{d}, \mathrm{~mm}$ & 5 & $5 ; 9$ \\
\hline Extrusion ratio during extruding $\mu$ & $6,5-15,3$ & $6,5-27,8$ \\
\hline Billet temperature $T_{b},{ }^{\circ} \mathrm{C}$ & $480 ; 550$ & $480 ; 550$ \\
\hline Strain rate $\xi, \mathrm{s}^{-1}$ & 0,$5 ; 1,5$ & 0,$5 ; 1,5$ \\
\hline Hydraulic clamping force, $\mathrm{kN}$ & 300 & 400 \\
\hline
\end{tabular}




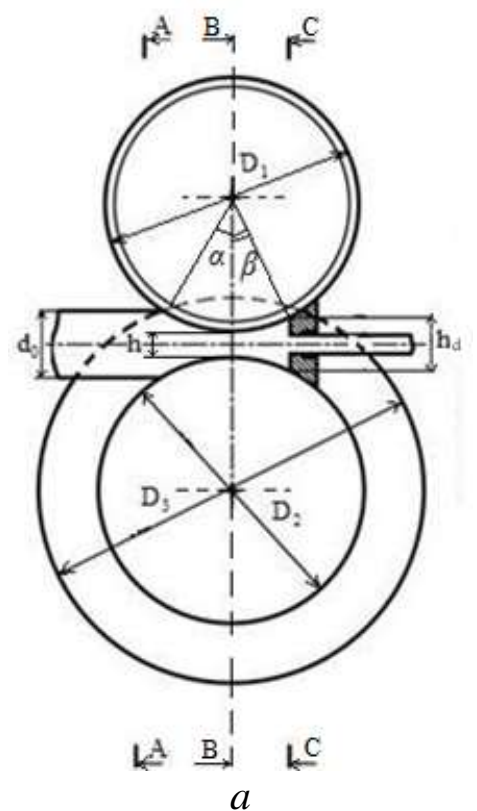

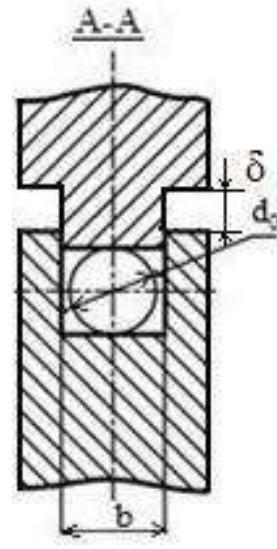

$b$

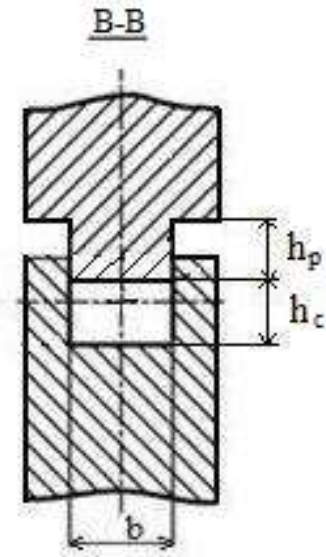

$c$

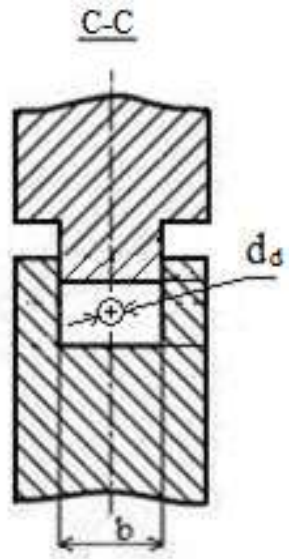

$d$

Fig. 2. Scheme of the process of combined rolling-extruding of a round billet in a closed box gauge: $a$-general view; $b$ - at the entrance to the deforming unit, $c$-during rolling, $d$-during extruding a rod from a die

When modeling using the DEFORM-3D complex the following conditions were accepted: the material of the rolls and dies is absolutely rigid; the diameter of the billet is $12 \mathrm{~mm}$, and the diameter of the extruded product is $5 \mathrm{~mm}$; the process takes place at a constant ambient temperature of $20{ }^{\circ} \mathrm{C}$; the temperature of the billet is taken equal to $550{ }^{\circ} \mathrm{C}$, and the temperature of the tool is $200{ }^{\circ} \mathrm{C}$; for calculations, the billet was divided into 10000 finite elements; the frequency of rotation of the rolls $\omega$ varied at two levels (4 and $8 \mathrm{rpm}$ ); Siebel friction coefficient was: on the contact surface of the roll - a billet equal 0.8 , at the border of the roll - a die equal 0.5 [21].

The microstructure of the metal was investigated using an Olympus GX51 optical microscope, an Axio Observer.A1m light microscope and an EVO 50 scanning electron microscope with an Inca Energy 350 energy dispersive spectrometer. Mechanical properties were determined using Walter + Bai AG LFM $400 \mathrm{kN}$ universal testing machines (for cast billets and extruded bars), LFM $20 \mathrm{kN}$ and WDW-20 with a force of $20 \mathrm{kN}$ (for wire). Specific electrical resistance $\rho$ was measured on samples $1 \mathrm{~m}$ long using a "Vitok" ohmmeter.

To measure force indicators during experimental studies on the CRE-200 unit, strain gauge equipment was used. It including CWW-50 CWW-100 force sensors with a maximum allowable compression force of $500 \mathrm{kN}$ and $1 \mathrm{MN}$ and a ZetLab ZET 017-T8 strain gauge station.

\section{Results and discussion}

Simulation results obtained using the DEFORM-3D software package are shown in Fig. 3. 


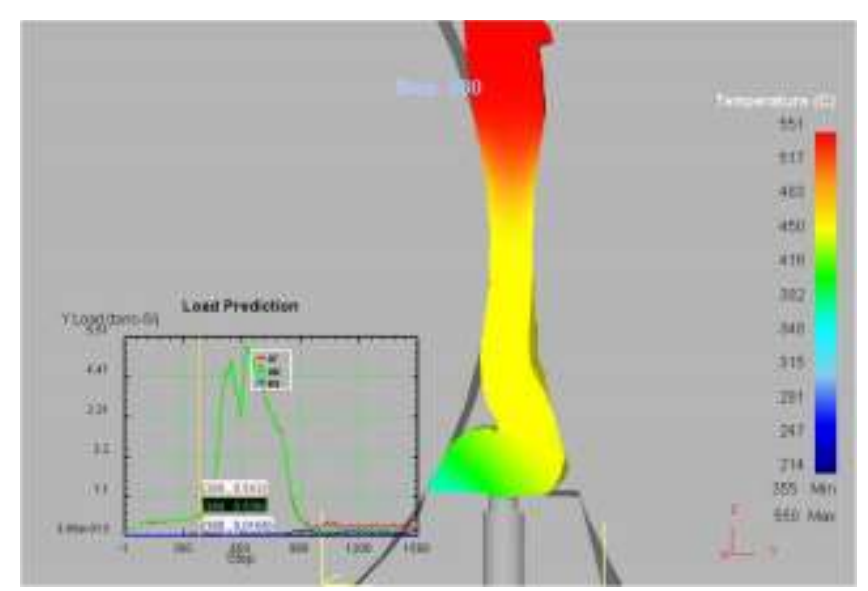

$a$

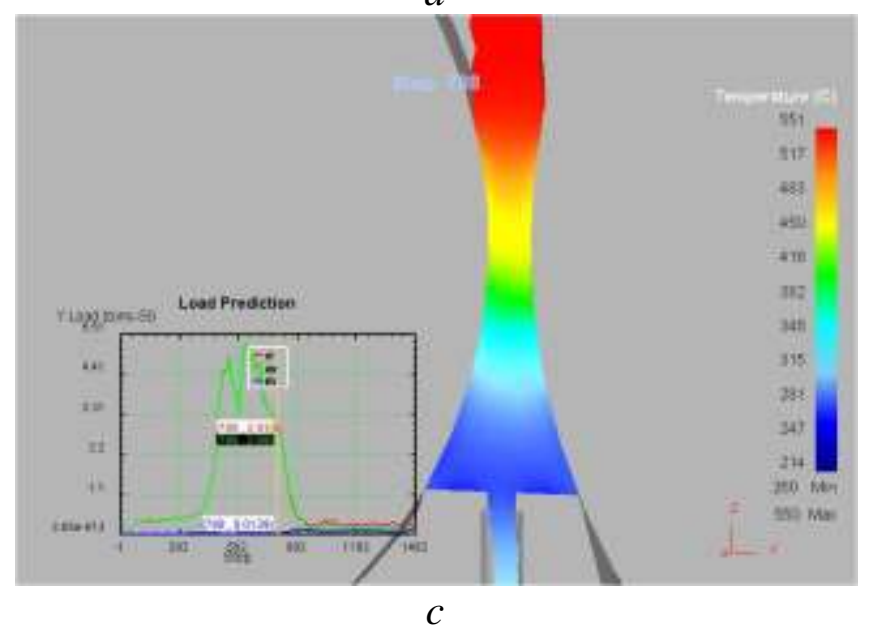

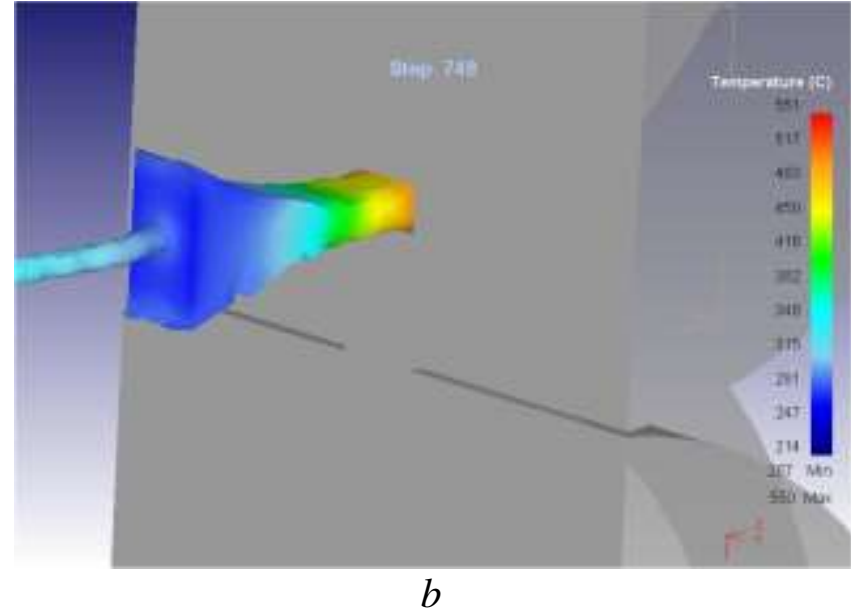

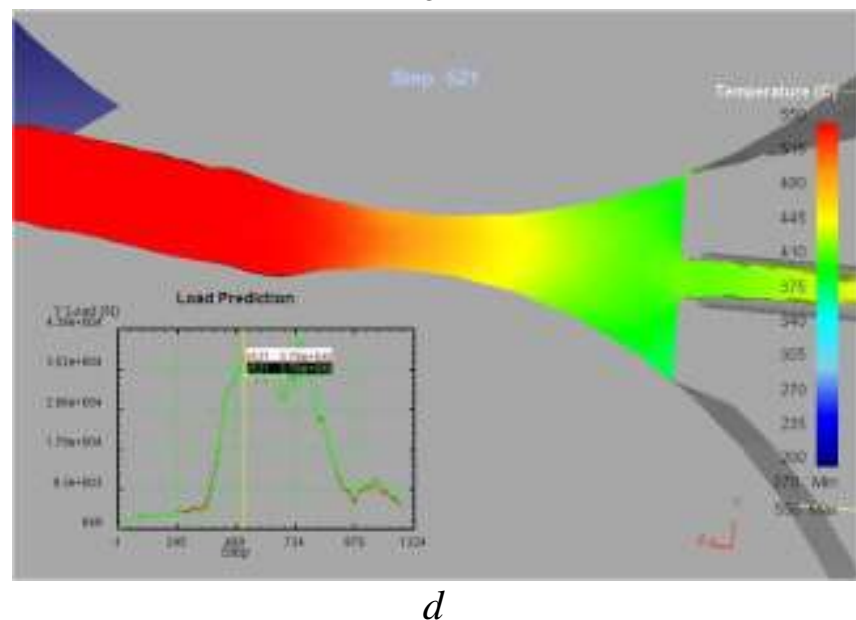

Fig. 3. Shaping of metal and temperature distribution along deformation zone in the simulation of the CRE process of a billet with a circular cross section: $a$ - the initial stage of deformation at $\omega=4$ rpm; $b$ - rolling stage at $\omega=4 \mathrm{rpm} ; c$ - extruding stage at $\omega=4 \mathrm{rpm} ; d$ - extruding stage $\omega=8 \mathrm{rpm}$

Analysis of the simulation results showed that the shape change of metal during processing of billet with a circular cross-section with a diameter of $12 \mathrm{~mm}$ in a closed box gauge on the CRE200 unit differs significantly from the shape change of a square billet. At the initial stage of the process at $\omega=4 \mathrm{rpm}$ (Fig. 3a), the billet with incomplete contact is captured by the rolls and compressed by the bottom surface of the roll with a groove and the ridge of the roll with a protrusion. It was found that at a given rotation frequency of $4 \mathrm{rpm}$, the rolls slip and a gradual decrease in the temperature of the billet in the extruding zone is observed (Fig. 3b) which can lead to a halt in the process. This is due to the fact that in the rolling zone there is a decrease in the contact area of the billet with the rolls along the corner elements of the groove and the value of the force supplied by the rolls decreases. At the same time the degree of metal reduction in height during rolling $(44 \%)$ does not exceed $50 \%$. Further, the billet metal reaches the die and extruded out, filling the caliber. When the pressure in the extruding zone is sufficient for extrusion, the metal is squeezed out in the form of a rod through a calibrating hole in the die (Fig. 3c).

Analysis of the metal temperature distribution showed that at the initial stage of the process, the billet is cooled from 550 to $450{ }^{\circ} \mathrm{C}$. Its temperature in the extruding zone at the start of extrusion of the rod is $330-340^{\circ} \mathrm{C}$. Further deformation leads to a decrease in the temperature in the extruding zone to $240-280{ }^{\circ} \mathrm{C}$. Therefore, for the case of the implementation of rolling-extruding at a roll rotation frequency of $4 \mathrm{rpm}$ with a rolling reduction ratio of less than $50 \%$ it is possible to stop the metal deformation process.

An increase in the rotation speed of the rolls to $8 \mathrm{rpm}$ significantly reduces the heat loss of the billet due to the shorter time of its contact with the rolls and the die having a temperature of 200 
${ }^{\circ} \mathrm{C}$. So in the plane of the smallest cross-section of the caliber the average temperature of the billet is $500{ }^{\circ} \mathrm{C}$, and at the stage of pressing and the beginning of extrusion of the rod it varies in the range of $410-445^{\circ} \mathrm{C}$. Further extrusion (Fig. $3 d$ ) leads to a decrease in the temperature of the metal in the extruding zone to $320^{\circ} \mathrm{C}$ and an increase in the temperature of the metal to $375^{\circ} \mathrm{C}$ which is typical for the steady-state of CRE process.

Thus, for a stable course of the combined rolling-extruding process on the CRE-200 unit of a billet with a diameter of $12 \mathrm{~mm}$ the following technological parameters of processing modes can be recommended based on the simulation results: billet temperature $550{ }^{\circ} \mathrm{C}$, temperature of rolls and die $200{ }^{\circ} \mathrm{C}$, roll rotation frequency $4-8 \mathrm{rpm}$; reduction in height when rolling is not less than $50 \%$.

As it was revealed during the simulation the possibility of carrying out the process CRE when using a round billet differs significantly from the deformation of a square or rectangular billet in a closed box caliber. Rolling such billets in a rectangular box gauge is possible only if certain conditions are met. It was found that for the guaranteed implementation of the process, it is necessary that the groove width of the box gauge is $5-15 \%$ greater than the diameter of the round billet which allows, on the one hand, to provide an unhindered supply of the heated billet in the gauge. And on the other hand, to control the guaranteed filling of the gauge with metal in width. When the width of the groove in comparison with the diameter of the billet is less than 5\%, due to the widening of the metal when it is heated the supply of the billet in the rolls and its capture by the rolls becomes difficult. To fill the caliber when the difference between the width of the groove of the roll and the diameter of the billet is more than $15 \%$, large height reductions are required during rolling. This is significantly increases the energy and power costs during metal deformation. In addition, for the implementation of the CRE process it is necessary to have a given height on a roll with a ridge protrusion which should be determined. When rolling-extruding a billet with a circular cross-section the redistribution of metal in the caliber occurs unevenly. And during rolling the caliber may not be completely filled. This can lead to a decrease in the contact forces of friction and, as a consequence, to slip of the rolls relative to the billet. As a result, the CRE process becomes unstable and the metal is not squeezed out through the die. In order to eliminate this drawback and ensure a stable process of metal extrusion due to the guaranteed filling of the caliber with metal during rolling it is proposed to determine the height of the roll ridge with a protrusion based on the condition of equality of the areas of the initial round billet with a diameter $d_{0}$ and the area of the upset rectangular billet after rolling in the minimum section of the caliber (Fig. 2). Then, taking into account the specified distance between the roll barrels $\delta$, the height of the roll ridge with the protrusion $h_{p}$ can be found by the following formula [63]:

$$
h_{p}=\delta+d_{0}-\frac{0.25 \pi d_{0}^{2}}{b}
$$

And the condition for the feasibility of the CRE process for the case of deformation of a billet with a circular cross section will be written in the form:

$$
h_{p e} \geq h_{p},
$$

where $h_{p e}$ - experimental value of the roll protrusion height incorporated in the design of the combined processing unit (Table 3).

To calculate the force parameters, the data on the rheological properties of the experimental alloy was used (Fig. 1) and took into account the increase in energy consumption due to the cooling down of the billet during its supply in the rolls and the formation of a barb when the metal penetrates between the die and the rolls.

The force supplied by the rolls was determined by the formula [63]: 


$$
P_{r}=0.017 k_{b} \sigma_{S a v} D\left(\sqrt{\frac{\Delta h}{0.5 D}}+\beta\right)(b+h),
$$

where $\sigma_{S a v}$ - average resistance of the metal to deformation, taking into account the cooling of the metal in the rolls; $k_{b}$ - coefficient taking into account the thickness and temperature of the barb; $D$ average roll diameter; $\Delta h$ - absolute rolling reduction; $\beta$-distance angle of the die surface from the common axis of the rolls (Fig. 2).

The force acting on the die was found by the formula:

$$
P_{d}=1.57 k_{b} \sigma_{S a v}\left(1.642 F_{d} \ln \mu+0.5 \mu d_{d} l_{b}\right)
$$

where $\mu$-extrusion ratio during extruding; $l_{b}$ - size of the working belt of the die; $F_{d}$ - area of the pressed billet in front of the die surface.

As a result of calculations using the obtained formulas for the same caliber and dimensions during extruding (Table 4) it was found that the force acting on the rolls during processing on the industrial CRE-400 unit is higher than on the CRE-200 unit. This is due to the fact that the rolling diameters of the rolls in this case are larger, and accordingly the length of contact of the rolls with the metal is also larger. It has also been found that for the conditions of processing a round billet on CRE units the clamping force (Table 3) is not enough to press the die and the process will be unfeasible. Therefore, the temperature $T_{b}=550{ }^{\circ} \mathrm{C}$ should be chosen, then the maximum force required for extruding a rod with a diameter of $5 \mathrm{~mm}$ will not exceed $241 \mathrm{kN}$.

Table 4 - Values of power parameters for CRE units with the same caliber dimensions in a

\begin{tabular}{|c|c|c|c|c|c|c|c|}
\hline \multirow{2}{*}{\multicolumn{2}{|c|}{ Parameters }} & \multicolumn{3}{|c|}{$T_{b}=480^{\circ} \mathrm{C}$} & \multicolumn{3}{|c|}{$T_{b}=550^{\circ} \mathrm{C}$} \\
\hline & & $\mu=6.5$ & $\mu=12.7$ & $\mu=15.3$ & $\mu=6.5$ & $\mu=12.7$ & $\mu=15.3$ \\
\hline \multicolumn{8}{|c|}{ Unit CRE-200 } \\
\hline \multirow{2}{*}{$\xi=0.5 \mathrm{~s}^{-1}$} & $P_{r, \mathrm{kN}}$ & 515 & 543 & 572 & 279 & 297 & 314 \\
\hline & $P_{d,} \mathrm{kN}$ & 182 & 289 & 362 & 99 & 158 & 199 \\
\hline \multirow{2}{*}{$\xi=1.5 \mathrm{~s}^{-1}$} & $P_{r, \mathrm{kN}}$ & 599 & 631 & 673 & 334 & 355 & 382 \\
\hline & $P_{d,} \mathrm{kN}$ & 212 & 336 & 426 & 118 & 189 & 241 \\
\hline \multicolumn{8}{|c|}{ Unit CRE-400 } \\
\hline \multirow{2}{*}{$\xi=0.5 \mathrm{~s}^{-1}$} & $P_{r, \mathrm{kN}}$ & 732 & 773 & 814 & 397 & 422 & 447 \\
\hline & $P_{d}, \mathrm{kN}$ & 182 & 289 & 362 & 99 & 158 & 199 \\
\hline \multirow{2}{*}{$\xi=1.5 \mathrm{~s}^{-1}$} & $P_{r}, \mathrm{kN}$ & 852 & 898 & 958 & 476 & 505 & 543 \\
\hline & $P_{d,} \mathrm{kN}$ & 212 & 336 & 426 & 118 & 189 & 241 \\
\hline
\end{tabular}
minimum section of $7 \times 15 \mathrm{~mm}$

Fig. 4 shows a comparison of the graphs of the calculated force parameters of the continuous extruding process for laboratory processing conditions on the CRE-200 unit (caliber $7 \times 15 \mathrm{~mm}$ ) and for industrial conditions on the CRE-400 unit (caliber $10 \times 21 \mathrm{~mm}$ ) at different billet temperatures (Table 4).

It can be seen that for the CRE-400 unit the recommended parameters for experimental studies $\left(T_{b}=550{ }^{\circ} \mathrm{C}, \xi=0.5 \mathrm{~s}^{-1}\right)$ provide optimal power loading of the equipment over the entire range of values of the extruding ratio. On the basis of the calculations technological recommendations were prepared for laboratory research on the CRE-200 unit and pilot-industrial research on the production of rods from alloy 01417 on the CRE-400 unit using continuously cast billets of various diameters obtained using an electromagnetic mold. 

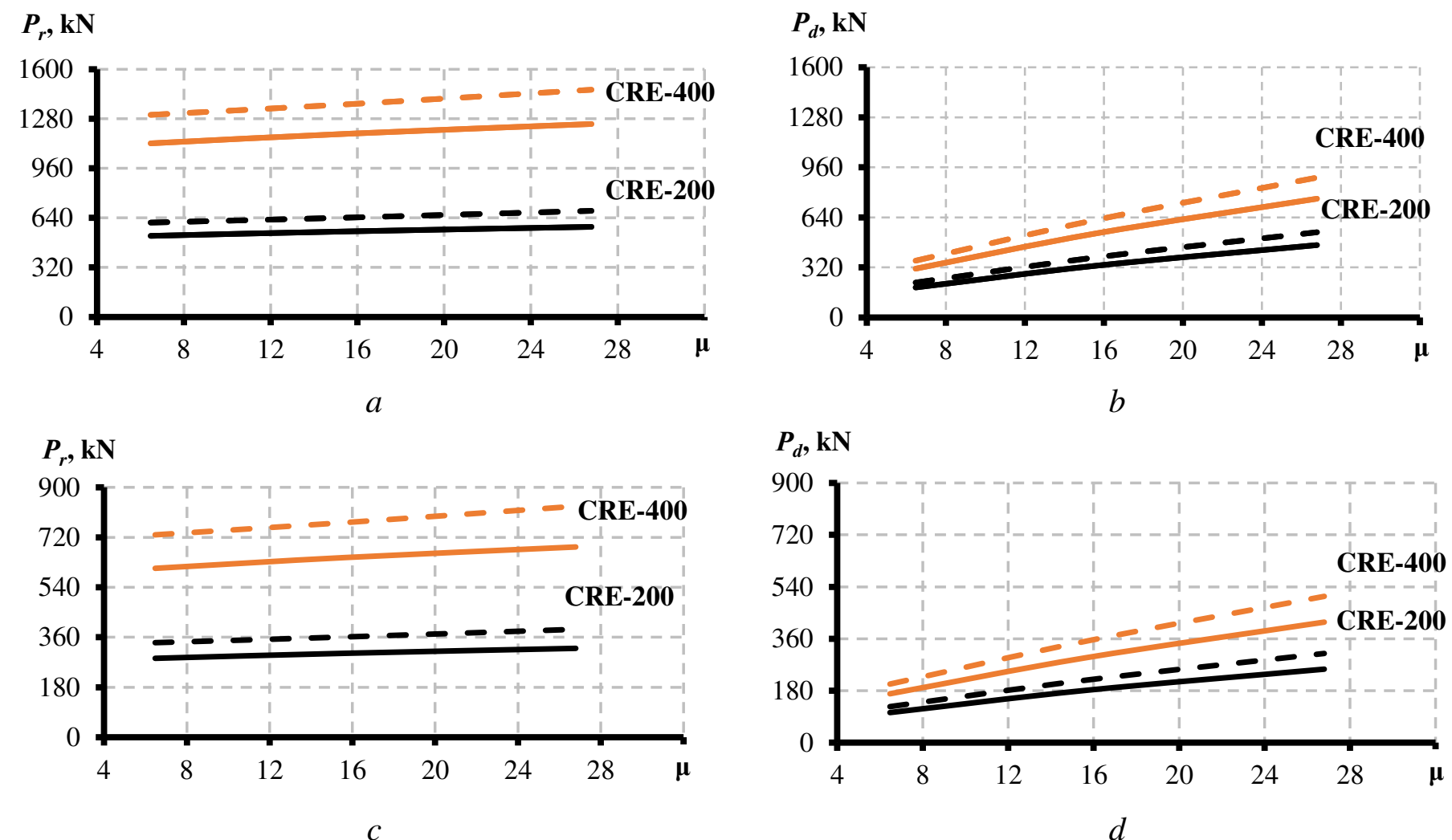

Fig. 4. Graphs of changes in the power parameters of the CRE process for the CRE-200 and CRE400 units with different caliber sizes: $a, b-T_{b}=480{ }^{\circ} \mathrm{C} ; c, d-T_{b}=550{ }^{\circ} \mathrm{C} ;-\xi=0.5 \mathrm{~s}^{-1}$;

$$
\xi=1.5 \mathrm{~s}^{-1}
$$

To carry out experimental studies, the design of a new unit for continuous casting, rolling and extruding of metal was proposed. The unit includes: a mixer furnace, an electromagnetic mold, a deforming unit consisting of a roll with a protrusion and a roll with a groove forming a working caliber, at the exit from which a die with wedge-shaped cavities for cooling is installed, pressed against the rolls using a hydraulic cylinder. A cooling device, a universal rolling stand and a device for product winding are installed in series behind the deforming unit [21-24, 49, 63, 64]. In order to use it for rolling a billet with a circular cross-section it is proposed to improve the deforming unit of the installation by making a box gauge, in which the groove width of the roll with the groove is greater than the billet diameter by $5-15 \%$. And the ridge of the roll with the protrusion to perform the given height taking into account the distance between the roll barrels, calculating it by the formula (1).

To study the influence of casting and annealing modes on the properties and structure of rods from the investigated alloy, obtained using EMM, at the LLC "Research and Production Center for Magnetic Hydrodynamics" (Krasnoyarsk), experimental billets were made at various casting temperatures of 670,740 and $780{ }^{\circ} \mathrm{C}$ and casting speeds of $4.4,10.8$, and $14.5 \mathrm{~mm} / \mathrm{s}$. The billets were heat treated at temperatures of $400,450,500$ and $550{ }^{\circ} \mathrm{C}$ for 2,4 and 8 hours. Analysis of the microstructure of the rods (Fig. 5) showed that with a decrease in the casting temperature the internal structure of the grain becomes coarser. The branches of dendrites become thicker and the parameter of the dendritic cell slightly increases. Annealing at a temperature of $550{ }^{\circ} \mathrm{C}$ causes degeneration of the eutectic and a uniform distribution of rare-earth aluminides is observed in the microstructure.

The results of determining the grain size in the cast billets of the experimental alloy showed that it is not the same over the section. In some areas of the peripheral zone, a fine-grained structure with a grain size of 31-64 microns is observed and a coarse-grained structure with a grain size from 
337 microns to 1410 microns is observed across the section. Therefore, hot deformation is required to work out the structure.

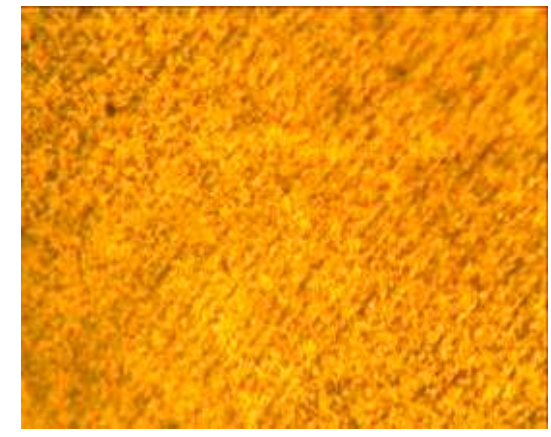

$a$

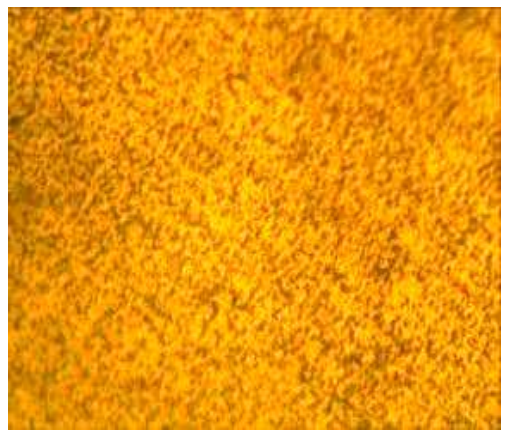

$b$

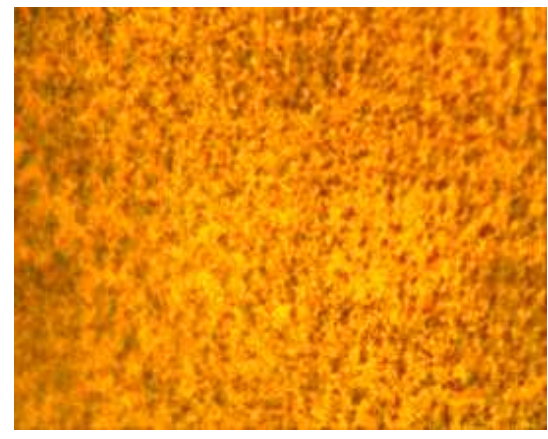

$c$

Fig. 5. Microstructure of annealed billets at temperature $T_{a}=550{ }^{\circ} \mathrm{C}$ with a diameter of $12 \mathrm{~mm}$ from a test alloy with casting speed of $10.8 \mathrm{~mm} / \mathrm{s}$ and different temperatures $T_{c}$ :

$$
a-T_{c}=670{ }^{\circ} \mathrm{C} ; b-T_{c}=740{ }^{\circ} \mathrm{C} ; c-T_{c}=780{ }^{\circ} \mathrm{C} ; \times 1000
$$

The properties of the obtained cast rods are given in Table 5.

Table 5 - Physical and mechanical properties of cast rods with a diameter of $12 \mathrm{~mm}$ from a test alloy obtained in EMM at different casting speeds

\begin{tabular}{|c|c|c|c|c|}
\hline \multirow{2}{*}{$\begin{array}{c}\text { Casting } \\
\text { speed }\end{array}$} & \multicolumn{4}{|c|}{ Properties } \\
\hline & $\begin{array}{l}\text { Ultimate tensile strength } R_{m}, \\
\mathrm{MPa}\end{array}$ & $\begin{array}{l}\text { Yield strength } R_{p}, \\
\mathrm{MPa}\end{array}$ & $\begin{array}{l}\text { Elongation to } \\
\text { failure } A, \%\end{array}$ & $\begin{array}{c}\text { Brinell hardness, } \\
\text { HBW }\end{array}$ \\
\hline $14.5 \mathrm{~mm} / \mathrm{s}$ & $\begin{array}{l}210 \\
205 \\
205\end{array}$ & $\begin{array}{l}110 \\
105 \\
111\end{array}$ & $\begin{array}{l}15.5 \\
12.4 \\
13.6\end{array}$ & 51.9 \\
\hline $10.8 \mathrm{~mm} / \mathrm{s}$ & $\begin{array}{l}205 \\
205 \\
205\end{array}$ & $\begin{array}{l}109 \\
111 \\
109\end{array}$ & $\begin{array}{l}17.2 \\
12.8 \\
21.9\end{array}$ & 51.8 \\
\hline $4.4 \mathrm{~mm} / \mathrm{s}$ & $\begin{array}{l}172 \\
170 \\
173 \\
\end{array}$ & $\begin{array}{l}91 \\
88 \\
89\end{array}$ & $\begin{array}{l}19.0 \\
23.8 \\
24.2\end{array}$ & 43.7 \\
\hline
\end{tabular}

The analysis of these data showed that the strength properties of cast billets increase with an increase in the casting speed, while the plasticity of the billets decreases, but remains at a fairly high level (12.4-15.5\%). With an increase in the annealing temperature to $550{ }^{\circ} \mathrm{C}$ and a duration of 8 hours, the elongation to failure increases to $38 \%$, the ultimate tensile strength decreases to $126 \mathrm{MPa}$ as compared to the cast state. However, the surface of the billets turns from shiny to matte gray.

In order to obtain billets for wire drawing the method of combined rolling-extruding was used [21-24, 49, 63, 64]. Experimental studies were carried out on a laboratory unit CRE-200 and an experimental-industrial unit CRE-400 (Table 6). During the experimental rolling-extruding on the CRE-200 unit the following technique was used. Several continuously cast billets $12 \mathrm{~mm}$ in diameter were simultaneously heated in an electric chamber furnace to a temperature of $550{ }^{\circ} \mathrm{C}$ and held for 10-15 min. The rolls and the die were heated to a temperature of $200{ }^{\circ} \mathrm{C}$, at which the rolls of the CRE-200 unit were brought into rotation at a speed of $4 \mathrm{rpm}$. The billets were sequentially set in the roll caliber, while the metal was pressed in height during rolling, pressed out in front of the matrix and squeezed out through it in the form of a rod. Then the rotational speed was increased to $8 \mathrm{rpm}$ and the experiments were repeated.

Table 6 - Technical characteristics of CRE units 


\begin{tabular}{|l|c|c|}
\hline \multirow{2}{*}{ Parameter } & \multicolumn{2}{c|}{ Value } \\
\cline { 2 - 3 } & CRE-200 & CRE-400 \\
\hline Nominal roll diameter, mm & 200 & 400 \\
\hline Rated torque, kNm & 22 & 35 \\
\hline Rotation frequency, rpm & 4,8 & $0-30$ \\
\hline Main motor power, $\mathrm{kW}$ & 19 & 18.5 \\
\hline Billet diameter, mm & $10-12$ & $12-18$ \\
\hline
\end{tabular}

The results of experimental studies of force parameters for obtaining rods with a diameter of $5 \mathrm{~mm}$ from a billet with a diameter of $12 \mathrm{~mm}$ from an experimental alloy in comparison with the calculated data are presented in Table 7.

Table 7 - Force parameters of the CRE process for a rod with a diameter of $5 \mathrm{~mm}$

\begin{tabular}{|c|c|c|c|c|}
\hline Force, $\mathrm{kN}$ & $\xi, \mathrm{s}^{-1}$ & Calculated data & Experimental data & Deviation, \% \\
\hline \multirow{2}{*}{$P_{r}$} & 0.5 & 314 & 348 & 9.8 \\
\cline { 2 - 5 } & 1.5 & 382 & 387 & 1.3 \\
\hline \multirow{2}{*}{$P_{d}$} & 0.5 & 199 & 181 & 9.0 \\
\cline { 2 - 5 } & 1.5 & 241 & 218 & 9.5 \\
\hline
\end{tabular}

Further, from extruded rods with a diameter of $5 \mathrm{~mm}$ on a chain drawing mill (Table 8) a wire with a diameter of $0.5 \mathrm{~mm}$ was obtained according to the developed route, subjecting an intermediate annealing to a semi-finished product with a diameter of $2.5 \mathrm{~mm}$.

Table 8 - Technical characteristics of the drawing mill

\begin{tabular}{|l|c|}
\hline \multicolumn{1}{|c|}{ Characteristics } & Characteristic values \\
\hline Length, mm & 2000 \\
\hline Number of working channels, pcs & 1 \\
\hline Drawing force, $\mathrm{kN}$ & 50 \\
\hline Drawing speed, $\mathrm{m} / \mathrm{s}$ & 0.17 \\
\hline Power consumption, $\mathrm{kW}$ & 25 \\
\hline
\end{tabular}

The results of testing the mechanical properties of the obtained cast and deformed semifinished products from the experimental alloy are presented in Table 9.

Table 9 - Mechanical properties of cast and deformed semi-finished products from a test alloy after continuous extruding by the CRE method and drawing

\begin{tabular}{|l|c|c|c|}
\hline \multirow{2}{*}{$\begin{array}{c}\text { Semi-finished product diameter } \\
(\mathrm{mm}) \text { and its condition }\end{array}$} & \multicolumn{3}{|c|}{ Mechanical properties } \\
\cline { 2 - 4 } & $\begin{array}{c}\text { Ultimate tensile strength } \\
R_{m}, \mathrm{MPa}\end{array}$ & $\begin{array}{c}\text { Yield strength } R_{p}, \\
\mathrm{MPa}\end{array}$ & $\begin{array}{c}\text { Elongation to } \\
\text { failure } A, \%\end{array}$ \\
\hline 12.0, cast & 182 & 102 & 11.8 \\
\hline 5.0, hot-extruded & 176 & 163 & 20.1 \\
\hline 0.5, cold-deformed & 250 & 181 & 1.3 \\
\hline 0.5, annealed $T_{a}=450^{\circ} \mathrm{C}, \tau=1 \mathrm{~h}$ & 143 & 124 & 19.1 \\
\hline 0.5, annealed $T_{a}=500^{\circ} \mathrm{C}, \tau=1 \mathrm{~h}$ & 137 & 119 & \\
\hline
\end{tabular}

The patterns of their change with an increase in the degree of deformation correspond to the traditional concepts of the theory of metal forming, while the ultimate tensile strength increases and elongation to failure decreases (Fig. 6) [22]. 

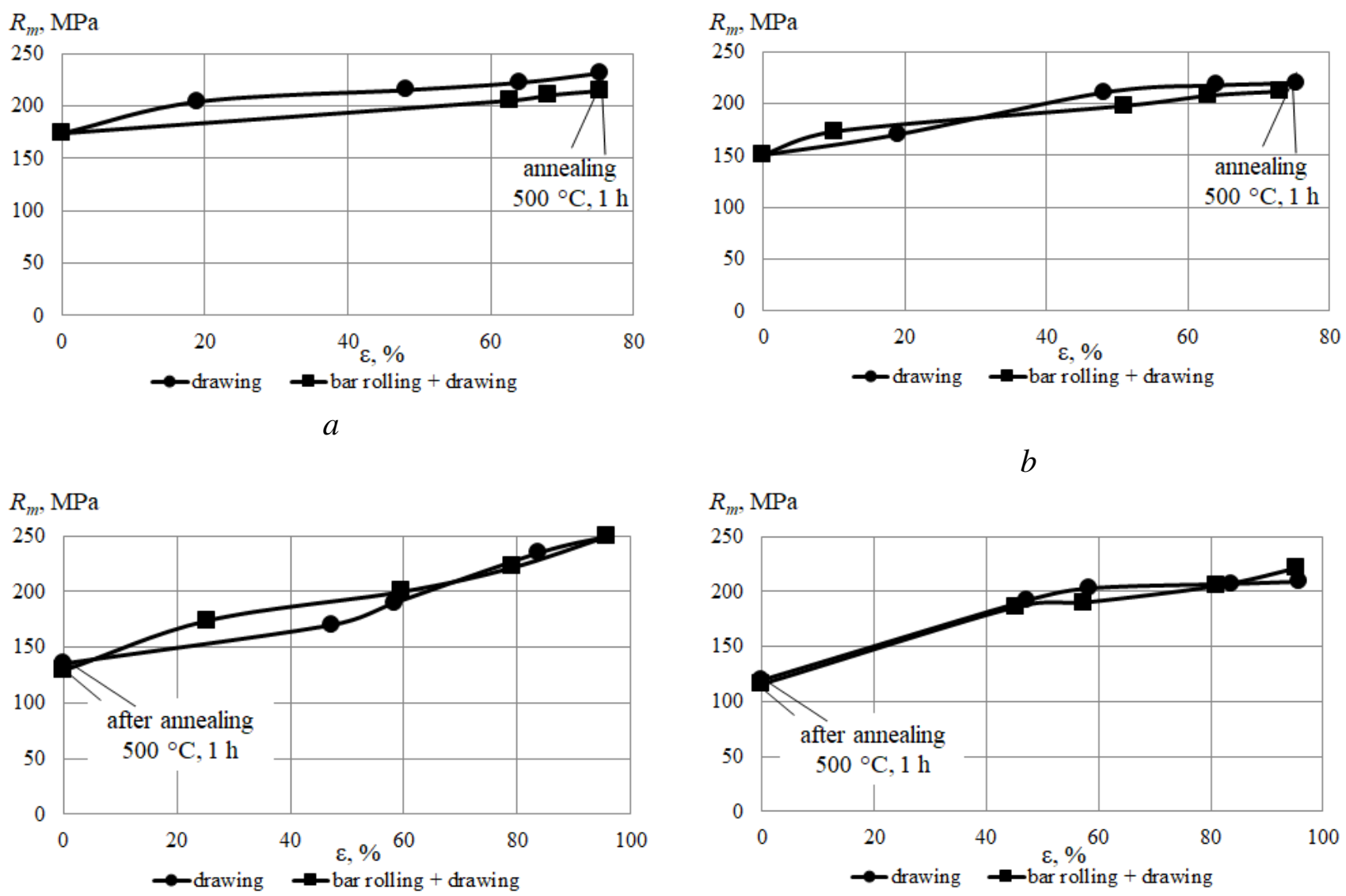

$c$
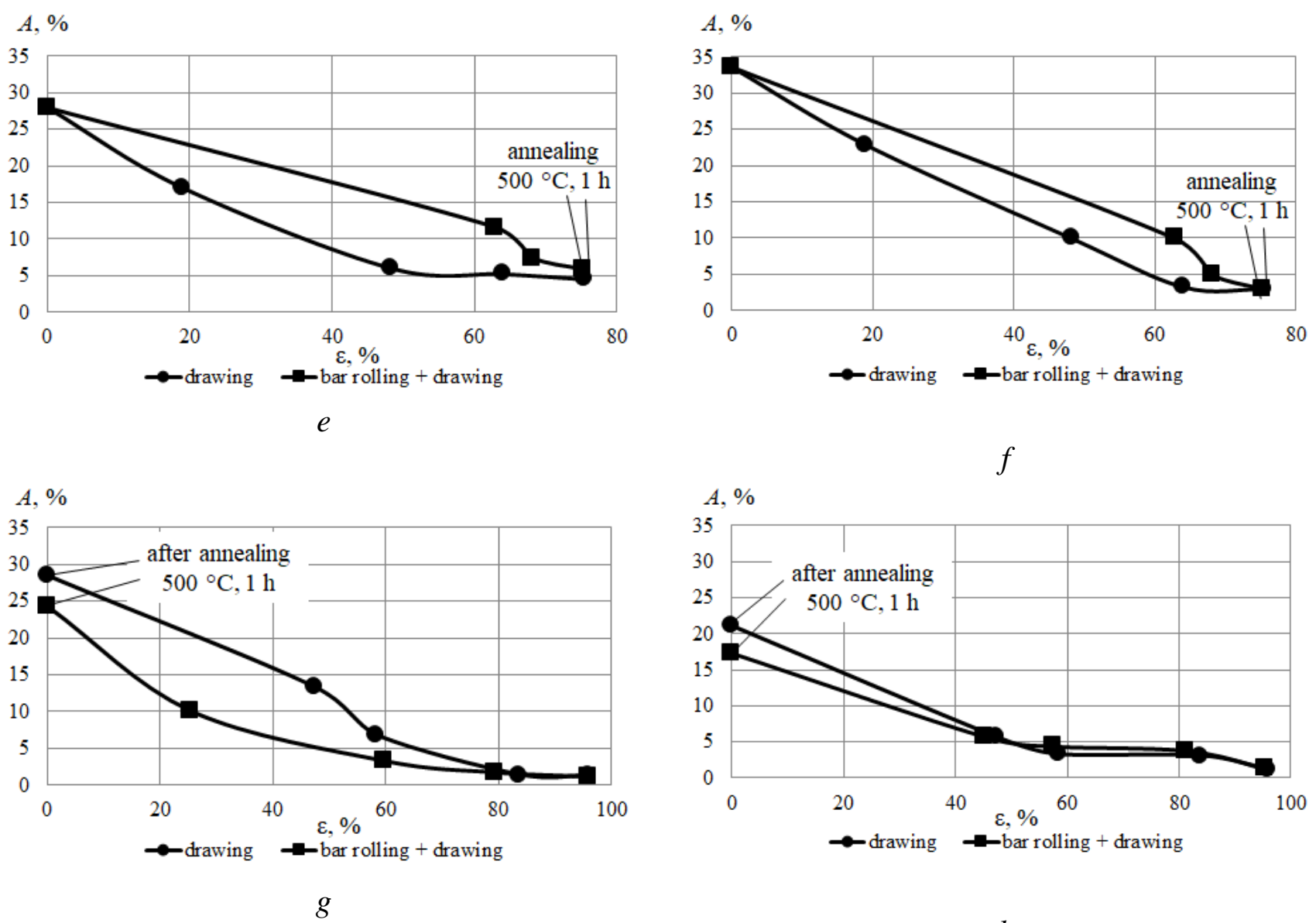
Fig. 6. Mechanical properties of deformed semi-finished products from a test alloy before and after annealing at different roll speeds: $a, c, e, g-4 \mathrm{rpm} ; b, d, f, h-8 \mathrm{rpm}$

It was found that annealing the wire at a temperature of $500{ }^{\circ} \mathrm{C}$ and a holding time of 1 hour leads to a decrease in the ultimate tensile strength to a value of $137 \mathrm{MPa}$ and an increase in the relative elongation to $19.1 \%$. Even higher ductility (elongation to failure 23.6-28.8\%) is possessed by a wire made from a billet obtained on an CRE unit with a roll rotation frequency of $8 \mathrm{rpm}$, which allows further cold deformation of the metal to obtain a wire with a diameter of about 0.1-0.2 mm. Measurements of the electrical resistance showed that their values for all modes of processing wire from an experimental alloy with a diameter of $0.5 \mathrm{~mm}$ in the annealed state are within the required limits $0.02919-0.03054 \mathrm{Ohm} \cdot \mathrm{mm}^{2} / \mathrm{m}$.

Metallographic studies of extruded rods (Fig. 7) showed that they have a uniform finegrained structure (Fig. 7a). The size of inclusions is insignificant and does not exceed $7 \mu \mathrm{m}$. After hot deformation the consequences of dendritic segregation were eliminated and instead of dendritic cells there was a uniform and dispersed distribution of REM aluminides over the cross section of the rods. The structure of a wire with a diameter of $0.5 \mathrm{~mm}$ in various states is shown in Fig. $7 b, c$. The analysis of the research results allowed to conclude that the wire made from a rod obtained on CRE unit with a roll rotation frequency of $4 \mathrm{rpm}$ has the required set of mechanical and electrical properties after annealing at a temperature of $500{ }^{\circ} \mathrm{C}$ and holding time of 1 hour.

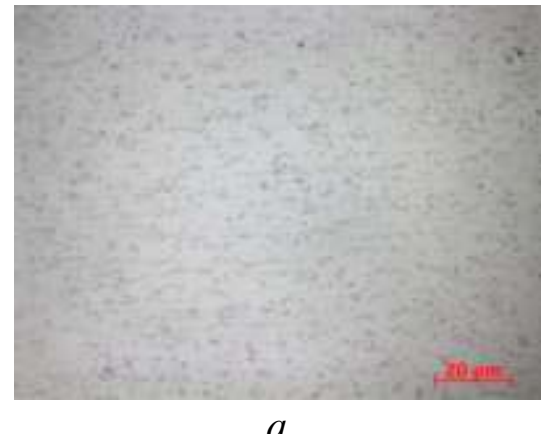

$a$

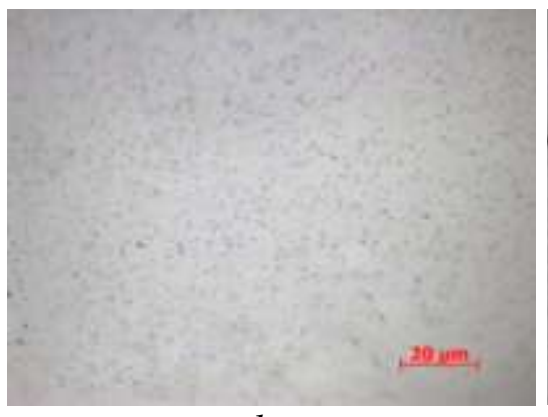

$b$

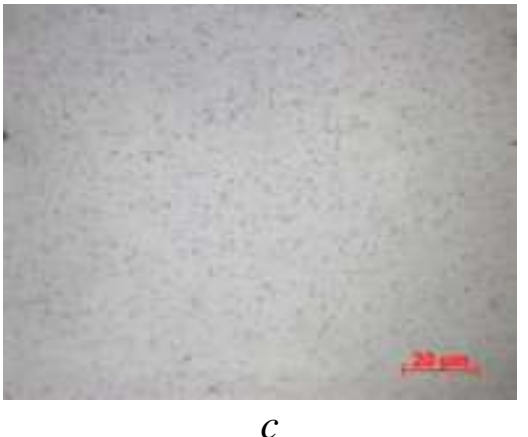

Fig. 7. Microstructure of a rod with a diameter of $5 \mathrm{~mm}(a)$ and a wire made of alloy 01417 with a diameter of $0.5 \mathrm{~mm}$ in deformed $(b)$ and annealed $(c)$ states, $\times 1000$

In order to obtain pilot batches of wire from alloy 01417 with a diameter of $0.5 \mathrm{~mm}$ with the required complex of physical and mechanical properties at the enterprises of LLC "Plant of Modern Materials" and LLC "Alliance 2008" (Krasnoyarsk) on the CRE-400 unit, hot-extruded rods were obtained for drawing with a diameter of $9 \mathrm{~mm}$. At the same time, based on the calculation of power costs and the feasibility of the process, as well as recommendations for the processing and annealing modes, the diameter of the continuously cast billet obtained in the EMM, the temperature and technological parameters of continuous extruding and subsequent drawing were selected.

On the CRE-400 unit, a coil of continuously cast billet with a diameter of $18 \mathrm{~mm}$ from an experimental alloy weighing $100 \mathrm{~kg}$ obtained in the EMM was processed. In accordance with the developed technique, continuously cast billets were heated to a temperature of $550{ }^{\circ} \mathrm{C}$ in an electric furnace and sent to rolls heated to a temperature of $200{ }^{\circ} \mathrm{C}$. The die, also heated to $200{ }^{\circ} \mathrm{C}$, was pressed against the rolls using a hydraulic cylinder and rolled-extruding was carried out. The resulting rod with a diameter of $9 \mathrm{~mm}$ was subjected to drawing to a diameter of $0.5 \mathrm{~mm}$ with intermediate annealing on a commercial drum-type drawing mill. It was found that extruding a billet heated to $550{ }^{\circ} \mathrm{C}$ at a roll and die temperature of $200{ }^{\circ} \mathrm{C}$ and a roll rotation speed of $8 \mathrm{rpm}$ can lead to the formation of temperature cracks along the length of the extruded rod. Subsequent experiments made it possible to recommend a roll rotation frequency of 2-4 rpm for the CRE-400 unit. The recommended technological parameters of the CRE process, thus, ensured the ability of 
the extruded rods to draw, which proceeded stably and without breaks while the wire had a shiny high-quality surface.

Electron microscopic studies of the microstructure of cold-deformed wire with a diameter of $0.5 \mathrm{~mm}$ (Fig. 8) were carried out in order to determine the particle size of REM aluminides and their distribution over the cross-section of the wire obtained under industrial conditions.

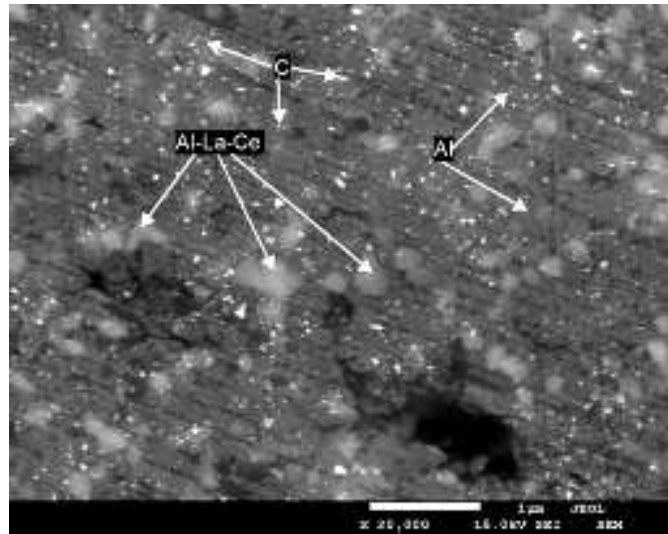

$a, \times 20000$

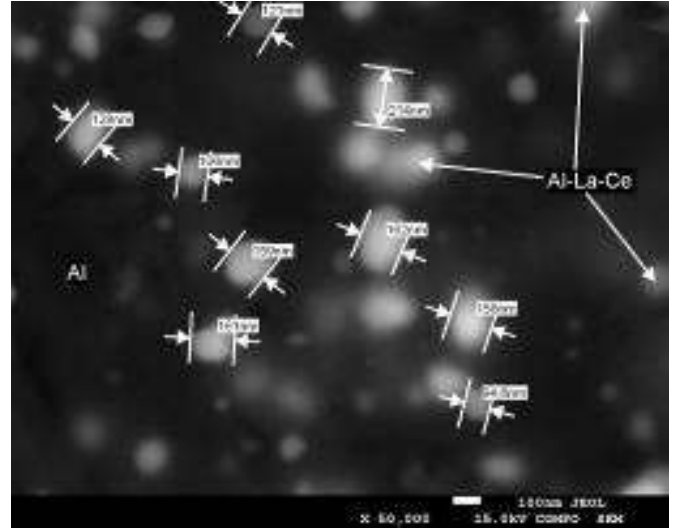

$b, \times 50000$

Fig. 8. Microstructure of a wire with a diameter of $0.5 \mathrm{~mm}$ from a test alloy in a cold-deformed state after drawing: $a$ - using SEI contrast, $b$ - using composite contrast COMPO

These data were necessary to determine their effect on the physical and mechanical properties of the wire and to justify the choice of the mode of its final annealing. The microstructure of the wire at enlargement of 20000 times (Fig. 8a) is characterized by the presence of dispersed and fairly uniformly distributed REM aluminides against the background of an aluminum solid solution. Determination of the size of aluminide particles with enlargement of 50000 (Fig. 8b) showed that they are 96-214 $\mathrm{nm}$. Figure 9 shows the results of determining the elemental composition of the wire and the microstructure using the COMPO and SEI contrast, which shows an aluminum matrix and light particles of lanthanum and cerium aluminides.
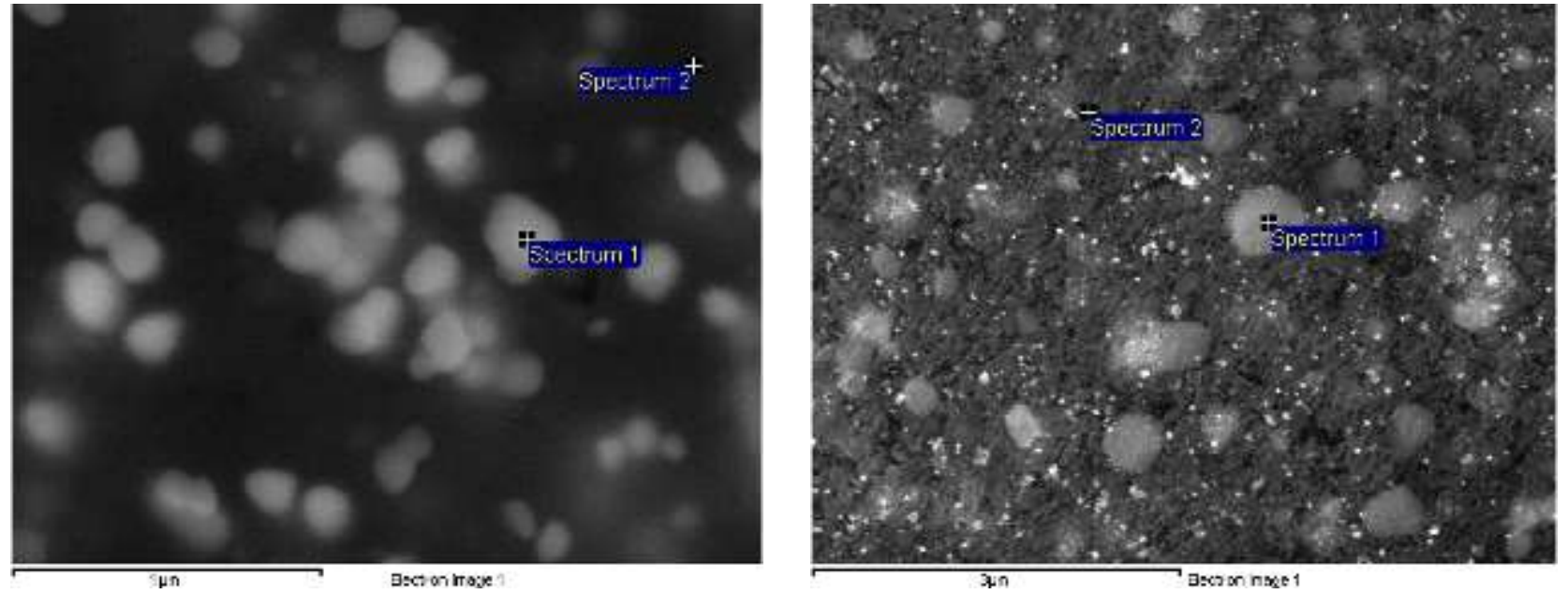

\begin{tabular}{|l|c|c|c|}
\hline \multicolumn{4}{|c|}{ All results in atomic \% } \\
\hline Spectrum & $\mathrm{Al}$ & $\mathrm{La}$ & $\mathrm{Ce}$ \\
\hline Spectrum 1 & 95.56 & 1.61 & 2.83 \\
\hline Spectrum 2 & 99.27 & - & 0.73 \\
\hline
\end{tabular}

$a, \times 20000$

\begin{tabular}{|l|c|c|c|}
\hline \multicolumn{4}{|c|}{ All results in atomic \% } \\
\hline Spectrum & $\mathrm{Al}$ & $\mathrm{La}$ & $\mathrm{Ce}$ \\
\hline Spectrum 1 & 94.25 & 1.88 & 3.87 \\
\hline Spectrum 2 & 99.19 & - & 0.81 \\
\hline
\end{tabular}

$b, \times 50000$ 
Fig. 9. Elemental composition and microstructure of a wire with a diameter of $0.5 \mathrm{~mm}$ from a test alloy in a cold-deformed state after drawing: $a$-using SEI contrast, $b$ - using composite contrast

COMPO

The results of testing the mechanical properties of the wire from the experimental alloy before and after the final annealing in different modes are presented in Table 10.

Table 10 - Physical and mechanical properties of a wire with a diameter of $0.5 \mathrm{~mm}$ from a test alloy obtained using the CRE-400 unit

\begin{tabular}{|l|c|c|c|}
\hline Condition and modes of annealing & \multicolumn{2}{|c|}{ Mechanical properties } & $\begin{array}{c}\text { Electrical } \\
\text { resistance } \rho, \\
\text { Ohm } \cdot \mathrm{mm}^{2} / \mathrm{m}\end{array}$ \\
\cline { 2 - 3 } & $\begin{array}{c}\text { Ultimate tensile } \\
\text { strength } R_{m}, \mathrm{MPa}\end{array}$ & $\begin{array}{c}\text { Elongation to } \\
\text { failure } A, \%\end{array}$ & 0.03151 \\
& 257 & 1.3 & 0.03157 \\
\hline Hardened & 260 & 1.2 & 0.03134 \\
Annealed, $T=400^{\circ} \mathrm{C}, \tau=4$ hours & 160 & 14.4 & 0.03137 \\
\hline Annealed, $T=450{ }^{\circ} \mathrm{C}, \tau=4$ hours & 159 & 14.2 & 0.03138 \\
& 160 & 15.6 & 0.03143 \\
\hline Annealed, $T=500{ }^{\circ} \mathrm{C}, \tau=4$ hours & 157 & 15.2 & 0.03139 \\
& 162 & 16.5 & 0.03132 \\
\hline
\end{tabular}

The developed modes of casting, continuous extruding, drawing and annealing, thus, made it possible to obtain commercial batches of wire with a diameter of $0.5 \mathrm{~mm}$ (Fig. 10) with the required level of properties.

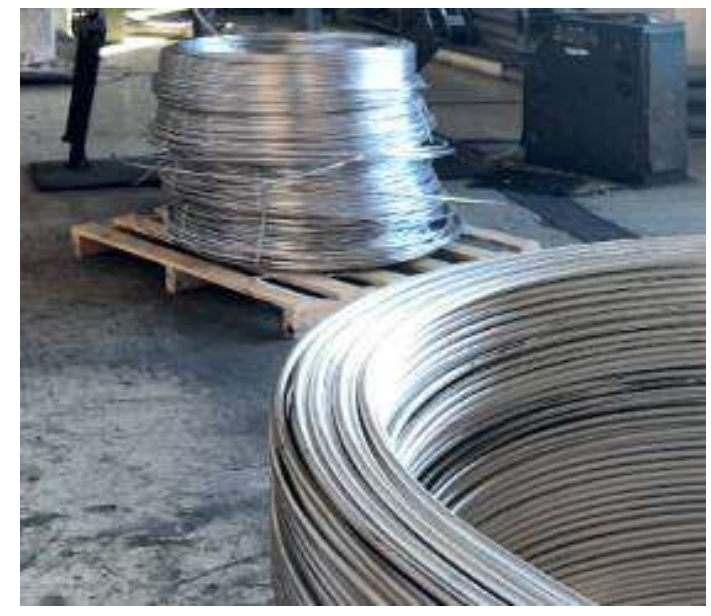

$a$

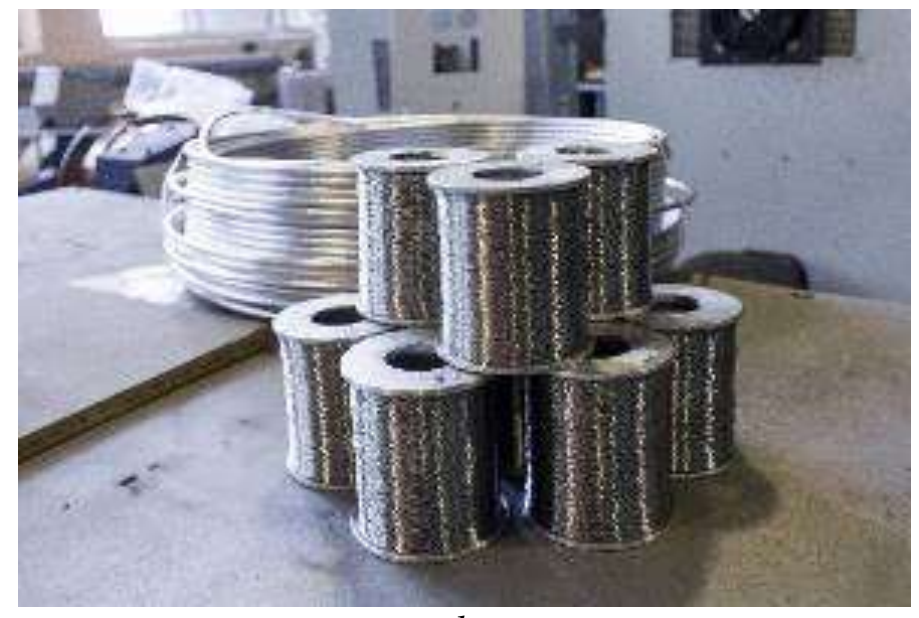

$b$

Fig. 10. Coils of a continuously cast billet (a) from experimental alloy cast by the EMM method and coils with a wire with diameter of $0.5 \mathrm{~mm}$ from this alloy obtained in industrial conditions $(b)$

For independent tests of the properties, measurements of the ultimate tensile strength, elongation to failure and electrical resistance at room temperature were carried out for 5 coils of the wire obtained at "Special Design Bureau of the Cable Industry" Ltd. (Moscow, Russian Federation). The test results confirmed the conclusion that the physical and mechanical properties of a wire with a diameter of $0.5 \mathrm{~mm}$ from an experimental alloy meet the requirements. According to test results the ultimate tensile strength for a wire with a diameter of $0.5 \mathrm{~mm}$ in the annealed state should not be lower than $142.5 \mathrm{MPa}$, the elongation to failure not lower than $8 \%$, and electrical resistance not higher than $0.03200 \mathrm{Ohm} \cdot \mathrm{mm}^{2} / \mathrm{m}$.

The study of the heat resistance of a wire with a diameter of $0.5 \mathrm{~mm}$ from an experimental alloy was carried out in the testing laboratory of mechanical and climatic tests of samples, materials 
and components of "Research Complex of Technological Support Center" Ltd. (Novosibirsk, Russian Federation) at various temperatures of 180,240 and $310^{\circ} \mathrm{C}$ and holding times of 1 and 400 hours. As a result of the tests it was found that the wire from the experimental alloy submitted for examination, produced according to the developed technology, meets the requirements.

\section{Summary}

Thus, as a result of the research the following main results were obtained:

1. Studied the rheological properties of continuously cast billets with a diameter of $12 \mathrm{~mm}$ from an experimental alloy of the Al-REM system with a rare-earth metal content of 7-9\%, made according to various casting modes in an electromagnetic mold, and obtained graphical dependences of the resistance of metal deformation on temperature, rate and degree of deformation in a given experimental conditions the range of their variation.

2. A computer 3D model of the combined rolling-extruding process was created for deformation of a billet with a circular cross-section and with its help the features of the shape change and temperature distribution in the deformation zone at different roll rotation frequency were studied using data on the rheological characteristics of the experimental alloy.

3. A method is proposed for the experimental and analytical assessment of the feasibility of the CRE process and for calculating the force characteristics during deformation of a billet with a circular cross-section, with the use of which the design parameters of the roll and extruding tool are determined, as well as the technological modes of continuous extruding for experimental research.

4. With the use of the developed technological modes of continuous casting in EMM, continuous extruding by the CRE method, drawing, intermediate and final annealing, experimental studies were carried out to obtain a wire with a diameter of $0.5 \mathrm{~mm}$ from an experimental alloy in laboratory and industrial conditions.

5. At all stages of these experimental studies the structure of the metal was investigated and the regularities of changes in the ultimate tensile strength, yield strength, elongation to failure and electrical resistance of longish deformed semi-finished products in the form of hot-extruded rods and wires in cold-deformed and annealed states were found depending on the processing modes.

6. Using the CRE-400 unit in industrial conditions rods with a diameter of $9 \mathrm{~mm}$ were extruded from a continuously cast billet with a diameter of $18 \mathrm{~mm}$, obtained using EMM; from which pilot batches of wire with a diameter of $0.5 \mathrm{~mm}$ were made from an experimental alloy of the Al-REM system containing rare earth metals of 7-9\% with the given physical and mechanical properties, while new deformation modes of continuous extruding and drawing routes, as well as modes of intermediate and final annealing have been developed.

\section{Declarations}

\section{Ethical Approval}

The work contains no libelous or unlawful statements, does not infringe on the rights of others, or contain material or instructions that might cause harm or injury.

\section{Consent to Participate}

The authors consent to participate.

\section{Consent to Publish}

The authors consent to publish.

\section{Authors Contributions}

The authors declare that they are all participants in the work and none of them performed only administrative functions. 


\section{Funding}

The research was carried out within the framework of the state assignment of the Ministry of Science and Higher Education of the Russian Federation (scientific theme code FSRZ-2020-0013).

\section{Competing Interests}

The authors declare about the absence of competing interests.

\section{Availability of data and materials}

Not applicable.

\section{References}

1. F. Czerwinski, Cerium in aluminum alloys. Journal of Materials Science, 2020, 55(1), $24-72$. https://doi.org/10.1007/s10853-019-03892-z. Accessed 01 Feb 2021

2. A. Tukker, Rare earth elements supply restrictions: Market failures, not scarcity, hamper their current use in high-tech applications. Environ. Sci. Technol, 2014, 48, 9973-9974. https://pubs.acs.org/doi/10.1021/es503548f. Accessed 01 Feb 2021

3. D.A. Chernavina, E.A. Chernavin, A.V. Faller, M.Yu. Zdanovich, Global aluminum market: development trends, prospects and key problems. Molodoy uchenyy, 2018, 17, 206-210.

4. Yu.A. Gorbunov, The Role and Prospects of Rare Earth Metals in the Development of PhysicalMechanical Characteristics and Applications of Deformable Aluminum Alloys. Journal of Siberian Federal University. Engineering \& Technologies, 2015, 8(5), 636-645. http://journal.sfukras.ru/en/article/19784. Accessed 01 Feb 2021

5. D.I. Belyy, Aluminium alloys for leads of cable products. Kabeli i Provoda, 2012, 1, 8-15.

6. V.I. Dobatkin, V.I. Elagin, V.M. Fedorov. Rapidly crystallized aluminum alloys. M. VILS. 1995.

7. V.P. Ceverdenko, N.V. Shepel'skiy, V.Z. Zhilkin. Pressure treatment of aluminum alloy granules. M: Metallurgiya. 1980.

8. TS 1-809-1038-2018. Electrotechnical wire of aluminum alloy mark 01417. Technical specifications. Publ. 13.06.2018.

9. F. Czerwinski, B.S. Amirkhiz, On the Al-Al11Ce3 eutectic transformation in aluminum-cerium binary alloys. Materials, 2020, 13(20), 4549. https://doi.org/10.3390/ma13204549. Accessed 01 Feb 2021

10. F. Czerwinski, Critical Assessment 36: Assessing differences between the use of cerium and scandium in aluminium alloying. Materials Science and Technology (United Kingdom), 2020, 36(3), 255-263. https://www.tandfonline.com/doi/full/10.1080/02670836.2019.1702775. Accessed 01 Feb 2021

11. J. W. Evans, The use of electromagnetic casting for Al alloys and other metals. JOM, 1995, 47, 38-41. https://link.springer.com/article/10.1007/BF03221174. Accessed 01 Feb 2021

12. Hai Hao, Xingguo Zhang, Shan Yao, Improvement of casting speed and billet quality of direct chill cast aluminum wrought alloy with combination of slit mold and electromagnetic coil. Materials Transactions, $2007, \quad$ 48(8), 2194-2201. https://www.jim.or.jp/journal/e/pdf3/48/08/2194.pdf. Accessed 01 Feb 2021

13. Masahiro Tani, Masafumi Zeze, Takehiko Toh, Keiji Tsunenari, Electromagnetic Casting Technique for Slab Casting. Nippon steel technical report, 2013, 104, 56-61. https://www.nipponsteel.com/en/tech/report/nsc/pdf/104-11.pdf Accessed 01 Feb 2021

14. Yu-bo Zuo, Jian-zhong Cui, Dan Mou, Qing-feng Zhu, Xiang-jie Wang, Lei Li, Effect of electromagnetic field on microstructure and macrosegregation of flat ingot of 2524 aluminium alloy. Transactions of Nonferrous Metals Society of China, 2014, 24, 2408-2413. https://www.sciencedirect.com/science/article/abs/pii/S1003632614633641. Accessed 01 Feb 2021

15. Hengcheng Liao, Yuna Wu, and Yongjin Wang, Microstructure Evolution of Al-0.35\%Si- 
$0.2 \% \mathrm{Mg}-0.3 \% \mathrm{Ce}$ Alloy During Hot Extrusion and Its Contributions to Performances. Journal of Materials Engineering and Performance, 2015, 24(6), 2503-2510. https://link.springer.com/article/10.1007/s11665-015-1485-2. Accessed 01 Feb 2021

16. Liao H., Liu Y., Lü C., Wang Q., Mechanisms for Ce-induced remarkable improvement of conductivity in Al alloys. Journal of Materials Research, 2017, 32(3), 566-574. https://www.cambridge.org/core/journals/journal-of-materials-research/article/abs/mechanisms-forceinduced-remarkable-improvement-of-conductivity-in-alalloys/9DD686C179F53B383C0A1E17B2527FB4\#. Accessed 01 Feb 2021

17. Shi Z.M., Gao K., Shi Y.T., Wang Y., Microstructure and mechanical properties of rare-earthmodified Al-1Fe binary alloys. Materials Science and Engineering: A, 2017, 632, 62-71. https://www.sciencedirect.com/science/article/abs/pii/S0921509315001963. Accessed 01 Feb 2021

18. Zhang Meng, Wang Haoyu, Han Wei, Zhang Milin, Li Yunna, Wang Yanli, Xue Yun, Ma Fuqiu, Zhang Xingmei, Electrochemical extraction of cerium and formation of Al-Ce alloy from $\mathrm{CeO} 2$ assisted by $\mathrm{AlCl} 3$ in $\mathrm{LiCl}-\mathrm{KCl}$ melts. Sci China Chem, 2014, 57(11), 1477-1482. https://link.springer.com/article/10.1007\%2Fs11426-014-5214-8. Accessed 01 Feb 2021

19. Mogucheva A., Zyabkin D., Kaibyshev R., Effect of the thermomechanical processing on microstructure and properties of an Al-Ce alloy. Materials Science Forum, 2012, 706-709, 361-366. https://doi.org/10.4028/www.scientific.net/MSF.706-709.361. Accessed 01 Feb 2021

20. Belov N.A., Alabin A.N., Teleuova A.R., Comparative analysis of alloying additives as applied to the production of heat-resistant aluminum-base wires. Metal Science and Heat Treatment, 2012, 53(9-10), 455-459. https://link.springer.com/article/10.1007/s11041-012-9415-5 Accessed 01 Feb 2021

21. Sidelnikov S., Sokolov R., Voroshilov D., Motkov M., Bespalov V., Voroshilova M., Sokolova S., Rudnitskiy E., Lebedeva O., Borisyuk V., Modeling the Process of Obtaining Bars from Aluminum Alloy 01417 by Combined Rolling-Extruding Method with Application of the Deform-3D Complex. Key Engineering Materials, 2020, 861, 540-546. https://doi.org/10.4028/www.scientific.net/KEM.861.540. Accessed 01 Feb 2021

22. S.B. Sidelnikov, D.S. Voroshilov, M.V. Pervukhin, M.M. Motkov, Development and research of technology for producing electrotechnical wire from alloys of the Al - REM system, obtained with the application of combined machining methods. Tsvetnye metally, 2019, 9, 63-68. https://www.rudmet.ru/journal/1853/article/31547/ Accessed 01 Feb 2021

23. S.B. Sidelnikov, V.N. Timofeev, Y.V. Gorokhov, D.S. Voroshilov, R.I. Galiev, M.M. Motkov, V.A. Kuzemchenko, P.N. Nikiforov, Comparative analysis of properties of wires from alloys of alrem system, obtained using the methods of continuous extrusion. International Journal of Engineering and Advanced Technology, 2019, 8(2), 300-304. https://www.ijeat.org/wpcontent/uploads/papers/v8i2s2/B10630182S219.pdf. Accessed 01 Feb 2021

24. S. Sidelnikov, D. Voroshilov, M. Motkov, M. Voroshilova, V. Bespalov, Development of Combined Machining Modes, Investigation of Mechanical Properties and Structure of Deformed Semi-Finished Products from Alloy 01417. Materials Science Forum, 2020, 992, 498-503. https://doi.org/10.4028/www.scientific.net/MSF.992.498. Accessed 01 Feb 2021

25. Zhang Yu., Wei F., Mao J., Niu G., The difference of $\mathrm{La}$ and $\mathrm{Ce}$ as additives of electrical conductivity aluminum alloys. Materials Characterization, 2019,158, 109963. https://www.sciencedirect.com/science/article/abs/pii/S1044580319312847?via\%3Dihub. Accessed 01 Feb 2021

26. Wan W., Han J., Li W., Wang J. Study of rare earth element effect on microstructures and mechanical properties of an Al-Cu-Mg-Si cast alloy. Rare Met. 25 (2006) 129-132. https://www.sciencedirect.com/science/article/abs/pii/S1001052108600662. Accessed 01 Feb 2021

27. He Ya., Liu J., Qiu Sh., Deng Zh., Zhang J., Shen Ya. Microstructure evolution and mechanical properties of Al-La alloys with varying La contents. Mater. Sci. Eng. A 701 (2017) 134-142. https://www.sciencedirect.com/science/article/abs/pii/S0921509317307876. Accessed 01 Feb 2021 
28. Yang Q., Bu F.Q., Meng F.C., Qiu X., Zhang D.P., Zheng T., Liu X.J., Meng J., The improved effects by the combinative addition of lanthanum and samarium on the microstructures and the tensile properties of high-pressure die-cast Mg-4Al-based alloy. Mater. Sci. Eng. A, 2015, 628, 319-326. https://www.sciencedirect.com/science/article/abs/pii/S0921509315000660. Accessed 01 Feb 2021

29. Jiang W., Fan Z., Dai Y., Li C., Effects of rare earth elements addition on microstructures, tensile properties and fractography of A357 alloy. Mater. Sci. Eng. A, 2014, 597, 237-244. https://www.sciencedirect.com/science/article/abs/pii/S0921509314000264. Accessed 01 Feb 2021

30. Huang X., Yan H., Effect of trace La addition on the microstructure and mechanical property of as-cast ADC12 Al-Alloy. J. Wuhan Univ. Technol.-Materials Sci. Ed., 2013, 28, 202-205.

31. Li P., Wu Z., Wang Y., Gao X., Wang Z., Li Zh., Effect of cerium on mechanical performance and electrical conductivity of aluminum rod for electrical purpose. J. Rare Earths, 2006, 24, 355357. https://www.sciencedirect.com/science/article/abs/pii/S1002072107604001. Accessed 01 Feb 2021

32. Yuan W., Liang Zh., Zhang Ch., Wei L., Effects of La addition on mechanical properties and thermal-resistant properties of Al-Mg-Si-Zr alloys based on AA6201. Mater. Des., 2012, 34, 788792. https://www.sciencedirect.com/science/article/abs/pii/S026130691100481X. Accessed 01 Feb 2021

33. Feng W., Jian M., Chunfang L., HuiHua L., Effect of trace elements La, Ti and homogenization on electrical properties of pure aluminum. Rare Metal Mater. Eng., 2018, 47, 3257-3263. https://www.sciencedirect.com/science/article/abs/pii/S1875537218302297. Accessed 01 Feb 2021 34. Lü, C.-L., Liao, H.-C., Liu, Y., Wang, Q.-G., Effect of Ce on castability, mechanical properties and electric conductivity of commercial purity aluminum. China Foundry, 2015, 12, 277284. http://ff.foundryworld.com/uploadfile/2015081939445589.pdf Accessed 01 Feb 2021

35. Cao X., Wang Sh., Wang Yi., The effect of annealing and aging on the high temperature internal friction spectra of Al-Ce alloy. Mater. Sci. Eng. B, 2009, 163, 174-178. https://www.sciencedirect.com/science/article/pii/S0921510709002396?via\%3Dihub Accessed 01 Feb 2021

36. Yao D., Xia Y., Qiu F., Jiang Q., Effects of La addition on the elevated temperature properties of the casting $\mathrm{Al}-\mathrm{Cu}$ alloy. Mater. Sci. Eng. A, 2011, 528, 1463-1466. https://www.sciencedirect.com/science/article/abs/pii/S0921509310012116. Accessed 01 Feb 2021 37. Du J., Ding D., Zhang W., Xu Z., Gao Y., Chen G., You X., Chen R., Huang Y., Tang J., Effect of $\mathrm{Ce}$ addition on the microstructure and properties of $\mathrm{Al}-\mathrm{Cu}-\mathrm{Mn}-\mathrm{Mg}-\mathrm{Fe}$ lithium battery shell alloy. $\begin{array}{llrr}\text { Mater. } & \text { Char., 2018, 252-260. }\end{array}$ https://www.sciencedirect.com/science/article/abs/pii/S1044580317335374. Accessed 01 Feb 2021 38. Tsai Y.C., Chou C.Y., Lee S.L., Lin C.K., Lin J.C., Lim S.W., Effect of trace La addition on the microstructures and mechanical properties of $\mathrm{A} 356(\mathrm{Al}-7 \mathrm{Si}-0.35 \mathrm{Mg})$ aluminum alloys. $\mathrm{J}$. Alloy. Comp., $\quad 2009, \quad 487$, 157-162. https://www.sciencedirect.com/science/article/abs/pii/S0925838809015813. Accessed 01 Feb 2021

39. Lu T., Pan Y., Wu J., Tao S., Chen Y., Effects of La addition on the microstructure and tensile properties of Al-Si-Cu-Mg casting alloys. Int. J. Miner. Metall. Mater., 2015, 22, 405-410. https://link.springer.com/article/10.1007/s12613-015-1086-y. Accessed 01 Feb 2021

40. Liao H.C., Liu Y., Lu C.L., Wang Q.G., Effect of Ce addition on castability, mechanical properties and electric conductivity of Al-0.3Si-0.2 Mg alloy. Int. J. Cast Metals Res., 2015, 28, $213-220$.

https://www.tandfonline.com/doi/abs/10.1179/1743133615Y.0000000002?journalCode=ycmr20.

Accessed 01 Feb 2021

41. Vijeesh V., Prabhu K.N., The effect of addition of Ce and Sr on the solidification path of Al8Si-2Cu alloy. Trans. Indian Inst. Met., 2015, 68, 1119-1123. https://link.springer.com/article/10.1007/s12666-015-0656-Z. Accessed 01 Feb 2021 
42. Gao G.Z., He Y.W., Chen J.Z., Effect of rare earth on conductivity of the aluminum wire. Chin. J. of Nonferrous Met., 1992, 2(1) 78-81.

43. Medvedev A.E., Murashkin M.Y., Enikeev N.A., Bikmukhametov I., Valiev R.Z., Hodgson P.D., Lapovok R., Effect of the eutectic Al-(Ce,La) phase morphology on microstructure, mechanical properties, electrical conductivity and heat resistance of Al-4.5(Ce,La) alloy after SPD and subsequent annealing. Journal of Alloys and Compounds, 2019, 796, 321-330. https://www.sciencedirect.com/science/article/abs/pii/S0925838819316640. Accessed 01 Feb 2021 44. Murashkin M.Y., Sabirov I., Medvedev A.E., Enikeev N.A., Lefebvre W., Valiev R.Z., Sauvage X., Mechanical and electrical properties of an ultrafine grained Al-8.5wt. \% RE ( $\mathrm{RE}=5.4 \mathrm{wt} . \% \mathrm{Ce}, 3.1 \mathrm{wt} . \% \mathrm{La}$ ) alloy processed by severe plastic deformation. Mater. Des., 2016, 90, 433-442. https://www.sciencedirect.com/science/article/abs/pii/S0264127515307413. Accessed 01 Feb 2021

45. Valiev R.Z., Murashkin M.Y., Sabirov I., A nanostructural design to produce high-strength Al alloys with enhanced electrical conductivity. Scripta Mater., 2014, 76, 13-16. https://www.sciencedirect.com/science/article/abs/pii/S1359646213006015. Accessed 01 Feb 2021

46. Matveeva I., Dovzhenko N., Sidelnikov S., Trifonenkov L., Baranov V., Lopatina E., Development and Research of New Aluminium Alloys with Transition and Rare-Earth Metals and Equipment for Production of Wire for Electrotechnical Applications by Methods of Combined Processing, Light Metals 2012 - TMS 2013 Annual Meeting and Exhibition, March 3, 2013 - March 7, 2013, Minerals, Metals and Materials Society, San Antonio, TX, United states, 2013, 443-447.

47. Mogucheva A.A., Zyabkin D.V., Kaibyshev R.O., Effect of annealing on the structure and properties of aluminium alloy Al-8\%MM. Met. Sci. Heat Treat., 2012, 53, 450-454. https://link.springer.com/article/10.1007/s11041-012-9414-

6\#: :text=Annealing $\% 20$ of $\% 20$ aluminum $\% 20$ alloy $\% 20 \mathrm{Al}$, transforms $\% 20$ into $\% 20 \mathrm{a} \% 20$ globular $\%$ 20phase.\&text=Annealing\%20at $\% 20600 \% \mathrm{C} 2 \%$ B0C $\% 20$ for $\% 2010 \% 20 \mathrm{~h} \% 20 \mathrm{yields} \% 20 \mathrm{a}$,longitudin al\%20and\%20transverse\%20direction\%20respectively. Accessed 01 Feb 2021

48. Medvedev A.E., Murashkin M.Y., Enikeev N.A., Valiev R.Z., Hodgson P.D., Lapovok R., Enhancement of mechanical and electrical properties of Al-RE alloys by optimising rare-earth concentration and thermo-mechanical treatment. J. Alloys Compd., 2018, 745, 696-704. https://www.sciencedirect.com/science/article/abs/pii/S0925838818307369. Accessed 01 Feb 2021 49. Sidelnikov S.B., Galiev R.I., Bersenev A.S., Voroshilov D.S., Application and Research Twin Roll Casting-Extruding Process for Production Longish Deformed Semi-Finished Products from Aluminum Alloys. Materials Science Forum, 2018, 918, 13-20. https://doi.org/10.4028/www.scientific.net/MSF.918.13. Accessed 01 Feb 2021

50. Ji C., Huang H., A review of the twin-roll casting process for complex section products. ISIJ $\begin{array}{llll}\text { International, } & 2020, & 60(10), & 2165-2175 .\end{array}$ https://www.jstage.jst.go.jp/article/isijinternational/60/10/60_ISIJINT-2020-149/_article. Accessed 01 Feb 2021

51. Avdulov A.A., Usynina G.P., Sergeev N.V., Gudkov I.S., Distinctive features of the structure and characteristics of long-length light gauge ingots from aluminium alloys, cast into $\begin{array}{lllll}\text { electromagnetic } & \text { crystallizer. } & \text { Tsvetnye } & \text { Metally, } & \text { 2017, }\end{array}$ https://www.rudmet.ru/journal/1645/article/28266/ Accessed 01 Feb 2021

52. Timofeev V., Khatsayuk M., Theoretical design fundamentals for MHD stirrers for molten metals. Magnetohydrogynamics, 2016, 595-506. http://www.mhd.sal.lv/Download/download.php?ed=rn\&vol=52\&nr=4\&an=6\&p1=495\&p2=495

Accessed 01 Feb 2021

53. Timofeev V., Khatsayuk M., Timofeev S., Analysis of transverse edge in MHD-stirrer of liquid metals. Magnetohydrogynamics, 2017, 53(3), 521-536. http://www.mhd.sal.lv/Download/download.php?ed=rn\&vol=53\&nr=3\&an=9\&p1=521\&p2=521

Accessed 01 Feb 2021 
54. M.V. Pervukhin, V.N. Timofeev, G.P. Usynina, N.V. Sergeev, M.M. Motkov, I.S. Gudkov, Mathematical modeling of MHD processes in the casting of aluminum alloys in electromagnetic mold. IOP Conf. Series: Materials Science and Engineering, 2019, 643, 012063. https://iopscience.iop.org/article/10.1088/1757-899X/643/1/012063. Accessed 01 Feb 2021

55. Korotkova N.O., Belov N.A., Timofeev V.N., Motkov M.M., Cherkasov S.O., Influence of Heat Treatment on the Structure and Properties of an Al-7\% REM Conductive Aluminum Alloy Casted in an Electromagnetic Crystallizer. Physics of Metals and Metallography, 2020, 121(2), 173-179. https://link.springer.com/article/10.1134/S0031918X2002009X. Accessed 01 Feb 2021

56. M.S. Gil'dengorn, V.V. Selivanov, Continuous extruding of pipes, profiles and wires using the Conform method. Light alloy technology, 1987, 4, 67-83.

57. V.L. Berezhnoy, V.N. Shcherba, A.I. Baturin. Extruding with active frictional forces. M.: Metallurgiya. 1988.

58. V.N. Shcherba. Extrusion of aluminum alloys. M.: Intermet-Inzhiniring. 2001.

59. G.I. Raab, E.I. Fakhretdinova, R.Z. Valiev, Development and Research of Method CCRE-SPD for Obtaining Aluminum Semi-Finished Products of High Quality. Journal of Siberian Federal University. Engineering \& Technologies, 2014, 3(7), 309-315. http://elib.sfukras.ru/bitstream/handle/2311/10379/09_Raab.pdf;jsessionid=4983562CC640A2A98E24C627F9E 84E49?sequence $=1$ Accessed 01 Feb 2021

60. Loginov Yu.N., Ershov A.A., Zagirov N.N., Ivanov E.V., Initiation of noncontact deformation zones in porous bar rolling-extrusion process. Forging and Stamping Production. Material Working by Pressure, 2017, 3, 38-41.

61. V.Z. Zhilkin, Yu.V. Gorokhov, V.M. Sergeev, F.S. Gilevich, Investigation of some parameters of continuous extrusion by the Conform method. Light alloy technology, 1984, 7, 10-15.

62. Kornilov V.N. Continuous extruding with welding of aluminum alloys. Krasnoyarsk: publishing house of the Pedagogical Institute. 1993.

63. S.B. Sidelnikov, N.N. Dovzhenko, N.N. Zagirov. Combined and complex methods of machining non-ferrous metals and alloys. M.: MAKS PRESS. 2005.

64. S.B. Sidelnikov, E.S. Lopatina, N.N. Dovzhenko, T.N. Drozdova, S.V. Belyaev, V.N. Baranov, I.L. Konstantinov, A.S. Sidelnikov, V.M. Bespalov. Features of structure formation and properties of metal during high-speed crystallization-deformation and modification of aluminum alloys: collective monograph. Krasnoyarsk: SibFU. 2015.

65. Yu.V. Gorokhov, V.G. Sherkunov, N.N. Dovzhenko, S.V. Belyaev, I.N. Dovzhenko. Fundamentals of designing processes for continuous extrusion of metals: monograph. Krasnoyarsk: SibFU. 2013.

66. N.A. Grishchenko, S.B. Sidelnikov, I.Yu. Gubanov, E.S. Lopatina, R.I. Galiev. Mechanical properties of aluminum alloys. Krasnoyarsk: SibFU. 2012.

67. S.B. Sidel'nikov, A.P. Samchuk, A.S. Sidel'nikov, D.S. Voroshilov, V.M. Bespalov, A.L. Trifonenkov, Research of rheological properties of electrotechnical wire rod of aluminum alloys with transition and rare earth metals obtained by the method of continious casting and metal forming. Bulletin of the South Ural State University. Ser. Metallurgy, 2015, 15(2), 89-95. https://vestnik.susu.ru/metallurgy/article/view/3590. Accessed 01 Feb 2021 


\section{Figures}

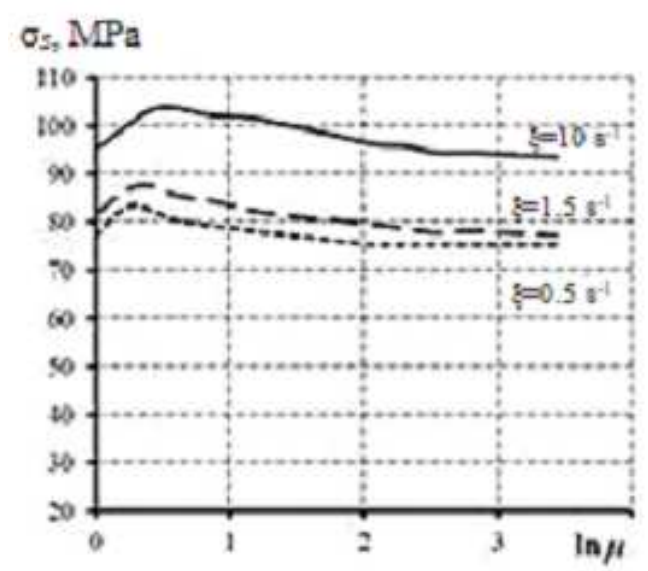

$a$

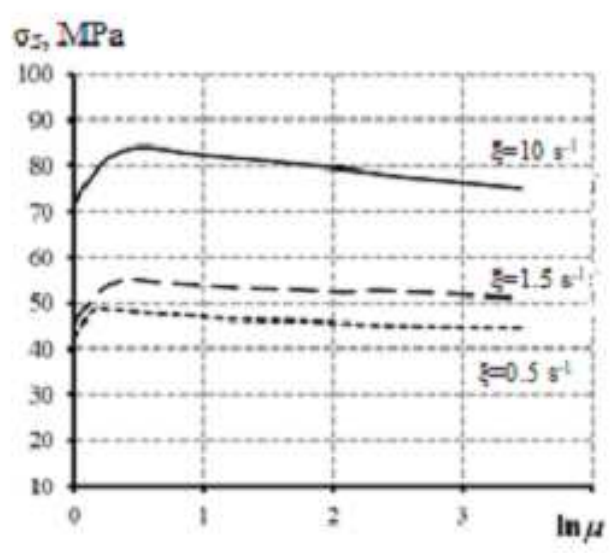

$b$

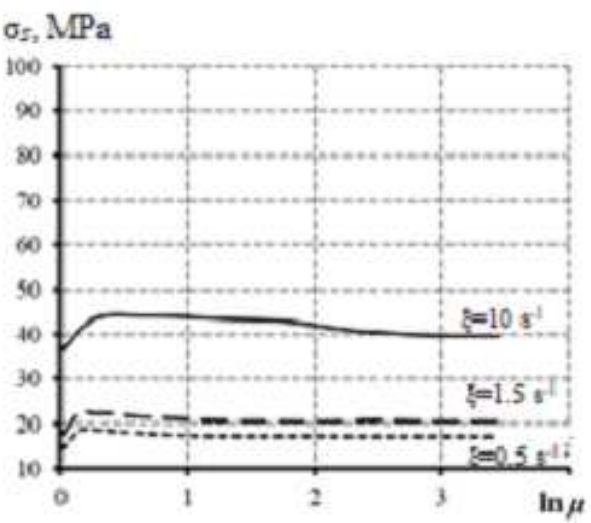

c

Figure 1

Dependence of the resistance to deformation os of the experimental alloy on the degree of deformation $\ln \mu$ at different rates of deformation $\xi$ and heating temperatures: $\mathrm{a}-320^{\circ} \mathrm{C} ; \mathrm{b}-400{ }^{\circ} \mathrm{C} ; \mathrm{c}-550{ }^{\circ} \mathrm{C}$

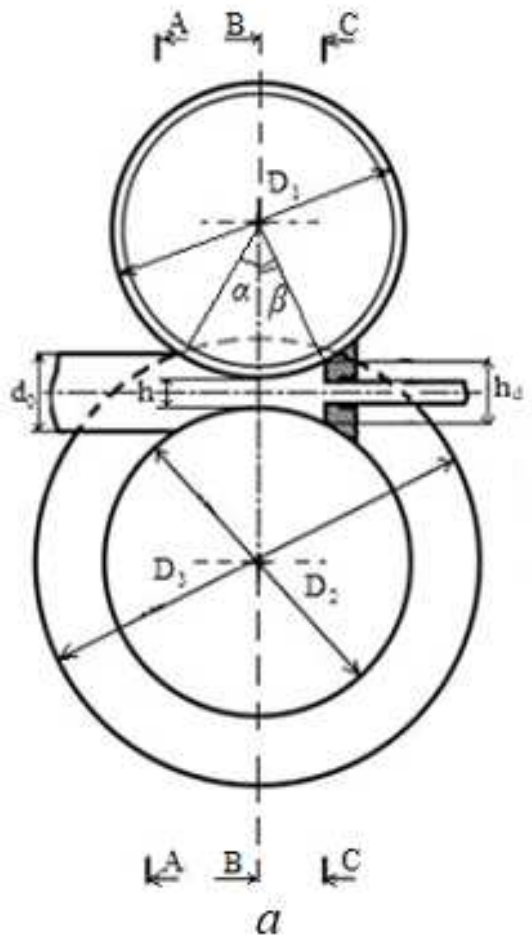

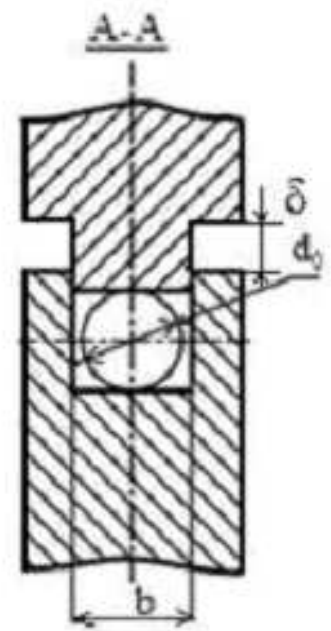

$b$

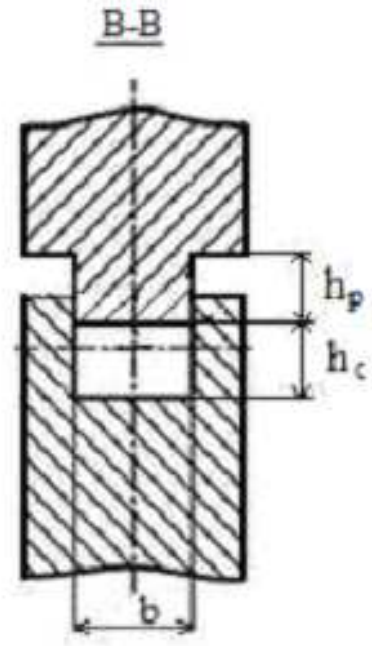

$c$

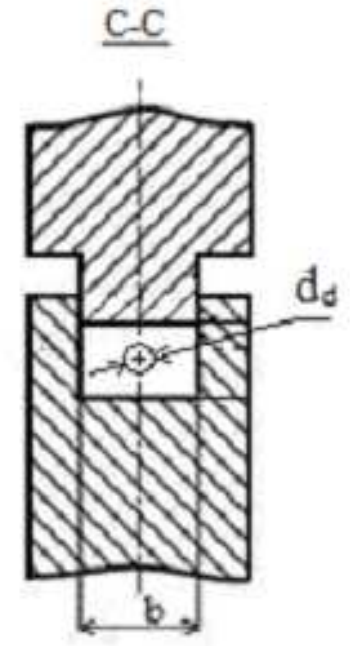

$d$

\section{Figure 2}

Scheme of the process of combined rolling-extruding of a round billet in a closed box gauge: a - general view; $b$ - at the entrance to the deforming unit, $c$ - during rolling, $d$ - during extruding a rod from a die 


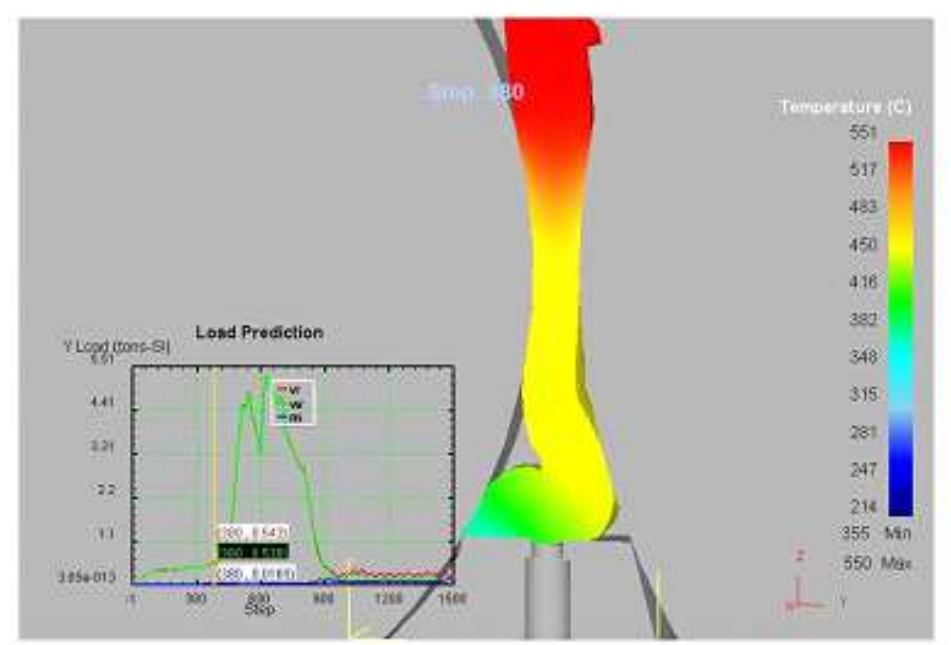

$a$

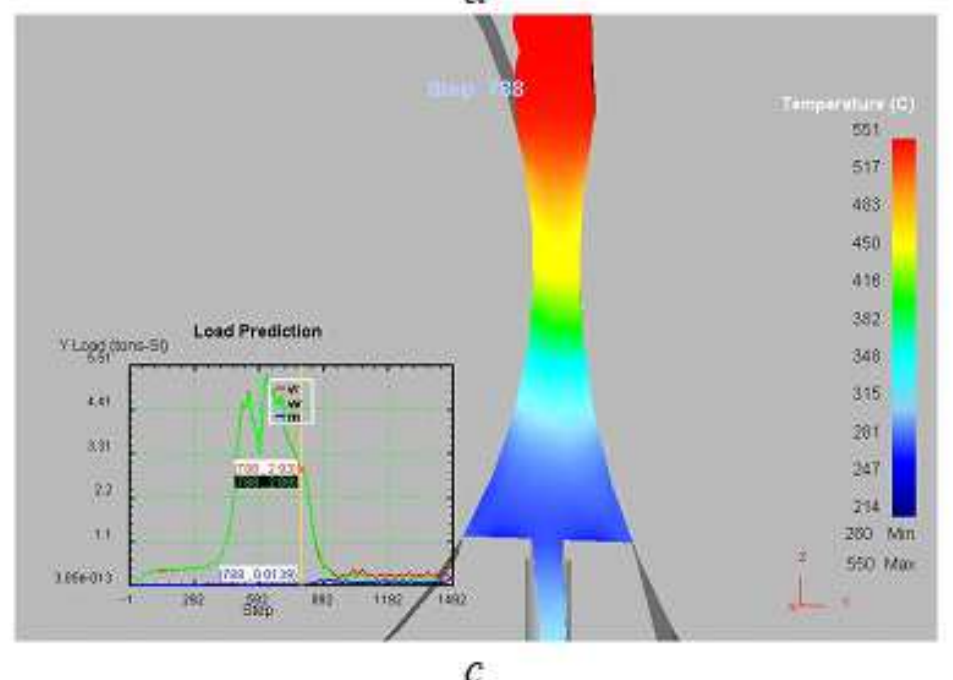

$c$

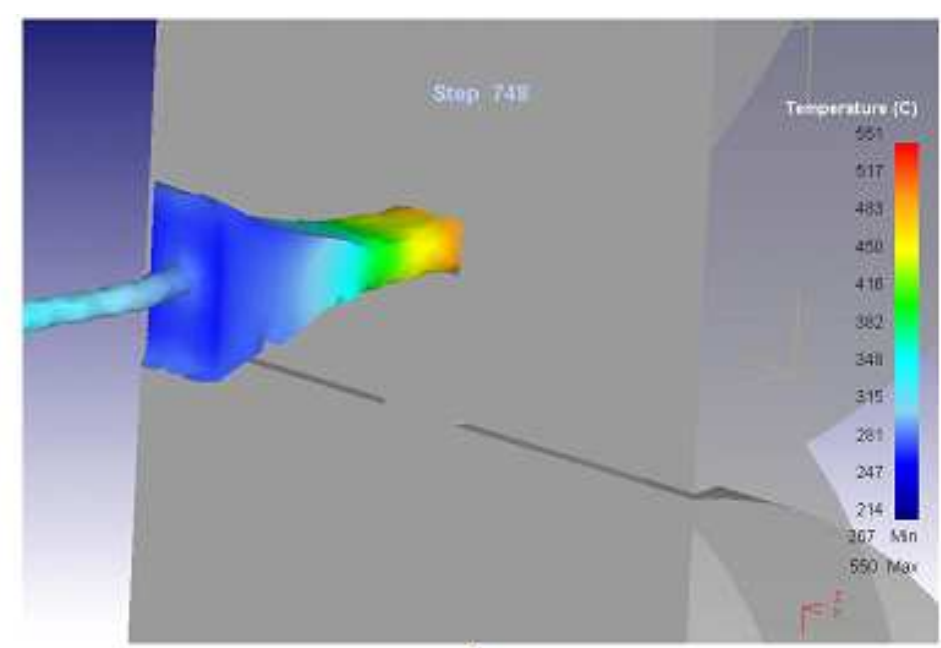

$b$

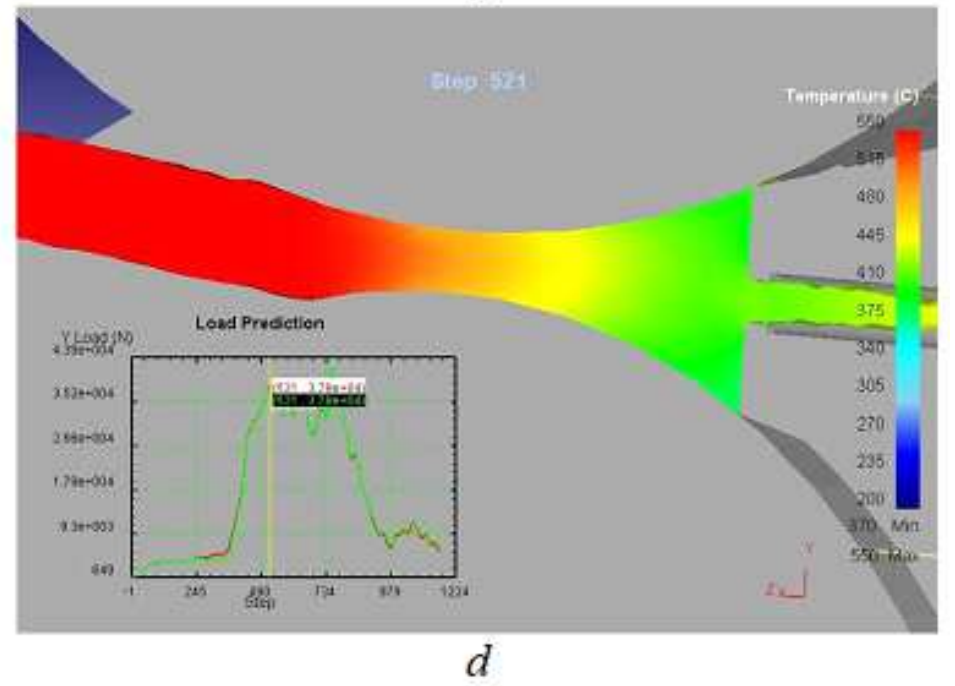

Figure 3

Shaping of metal and temperature distribution along deformation zone in the simulation of the CRE process of a billet with a circular cross section: $a-$ the initial stage of deformation at $\omega=4 \mathrm{rpm} ; \mathrm{b}-$ rolling stage at $\omega=4 \mathrm{rpm} ; c$ - extruding stage at $\omega=4 \mathrm{rpm} ; \mathrm{d}$ - extruding stage $\omega=8 \mathrm{rpm}$ 

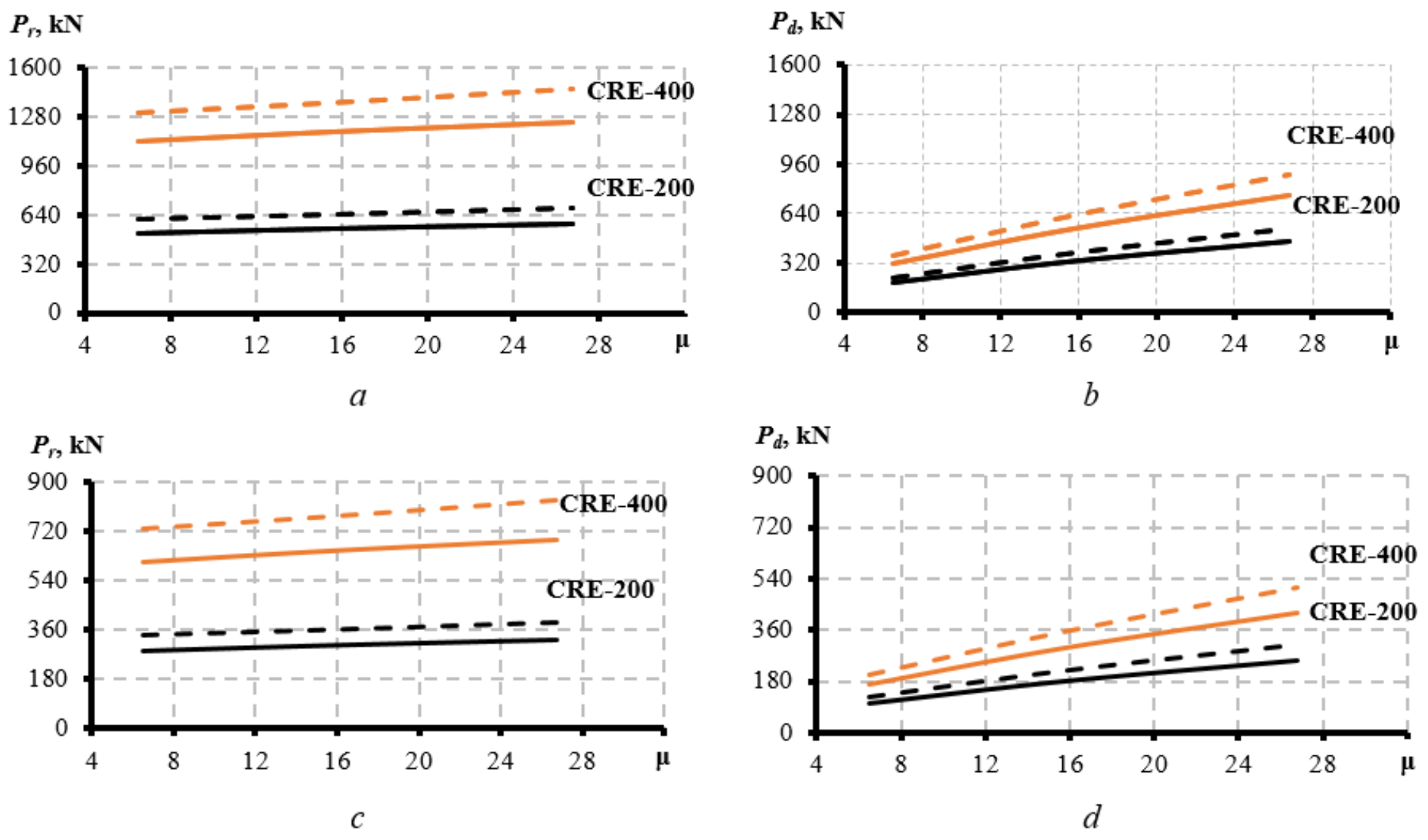

Figure 4

Graphs of changes in the power parameters of the CRE process for the CRE-200 and CRE-400 units with different caliber sizes: $\mathrm{a}, \mathrm{b}-\mathrm{Tb}=480^{\circ} \mathrm{C} ; \mathrm{c}, \mathrm{d}-\mathrm{Tb}=550{ }^{\circ} \mathrm{C} ;---\xi=0.5 \mathrm{~s}-1 ;---\xi=1.5 \mathrm{~s}-1$

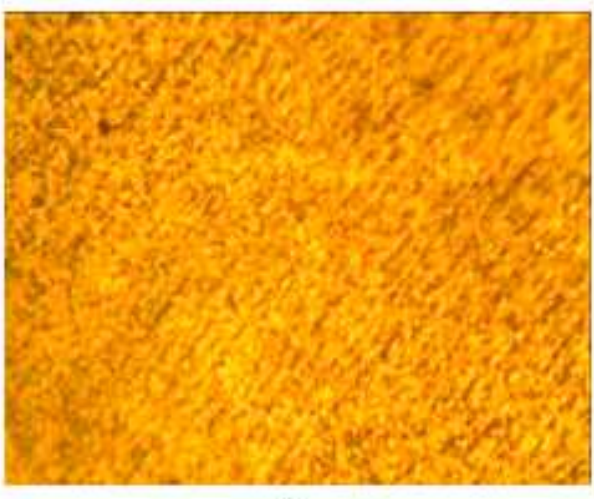

$a$

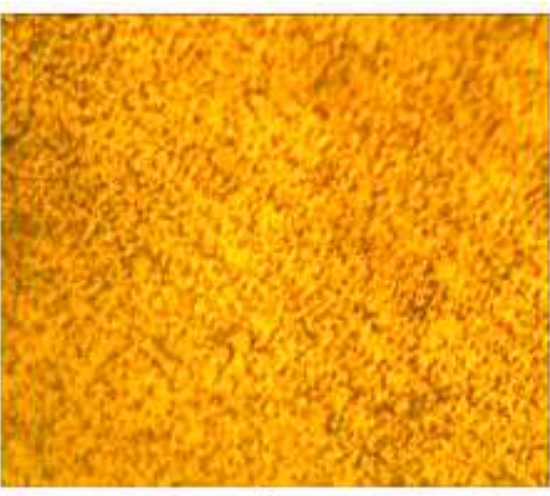

$b$

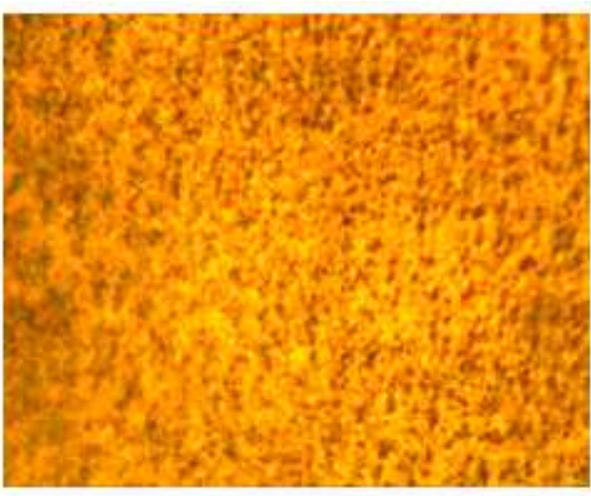

$c$

\section{Figure 5}

Microstructure of annealed billets at temperature $\mathrm{Ta}=550^{\circ} \mathrm{C}$ with a diameter of $12 \mathrm{~mm}$ from a test alloy

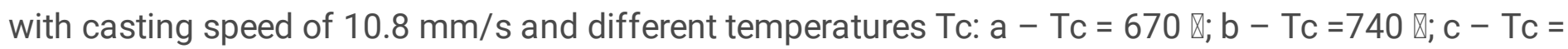
780 区; $\times 1000$ 


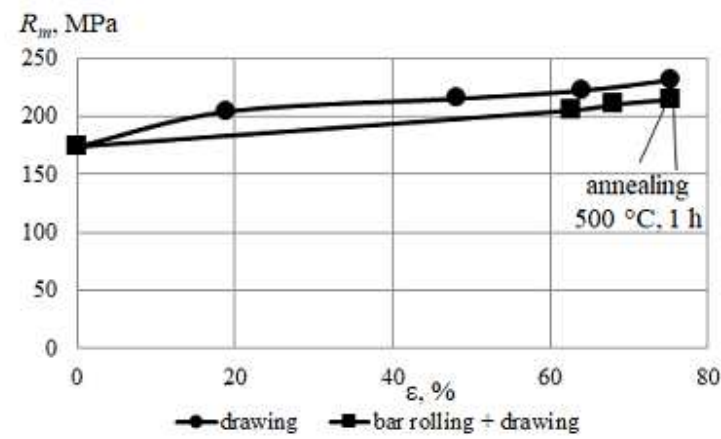

$a$

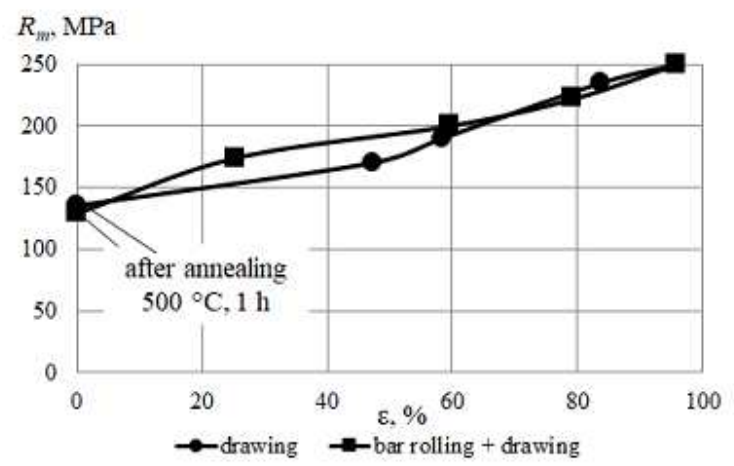

$c$
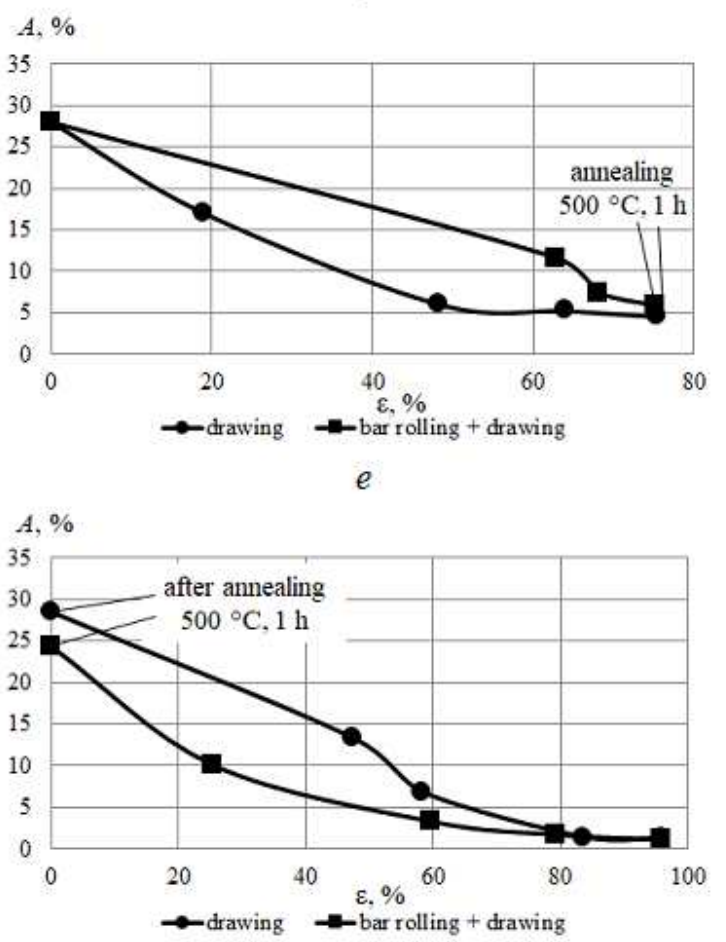

$g$

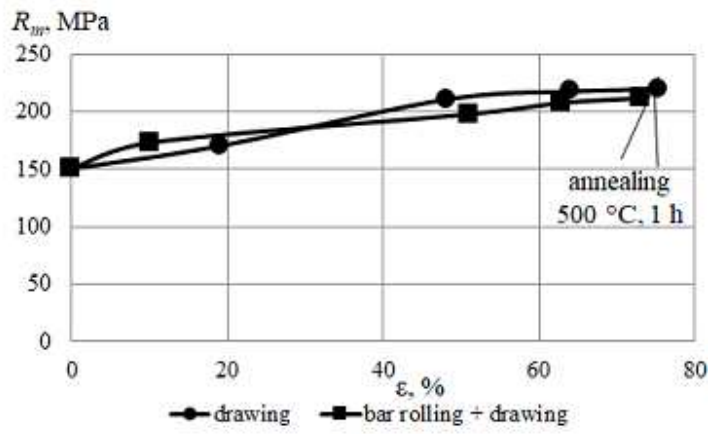

$b$
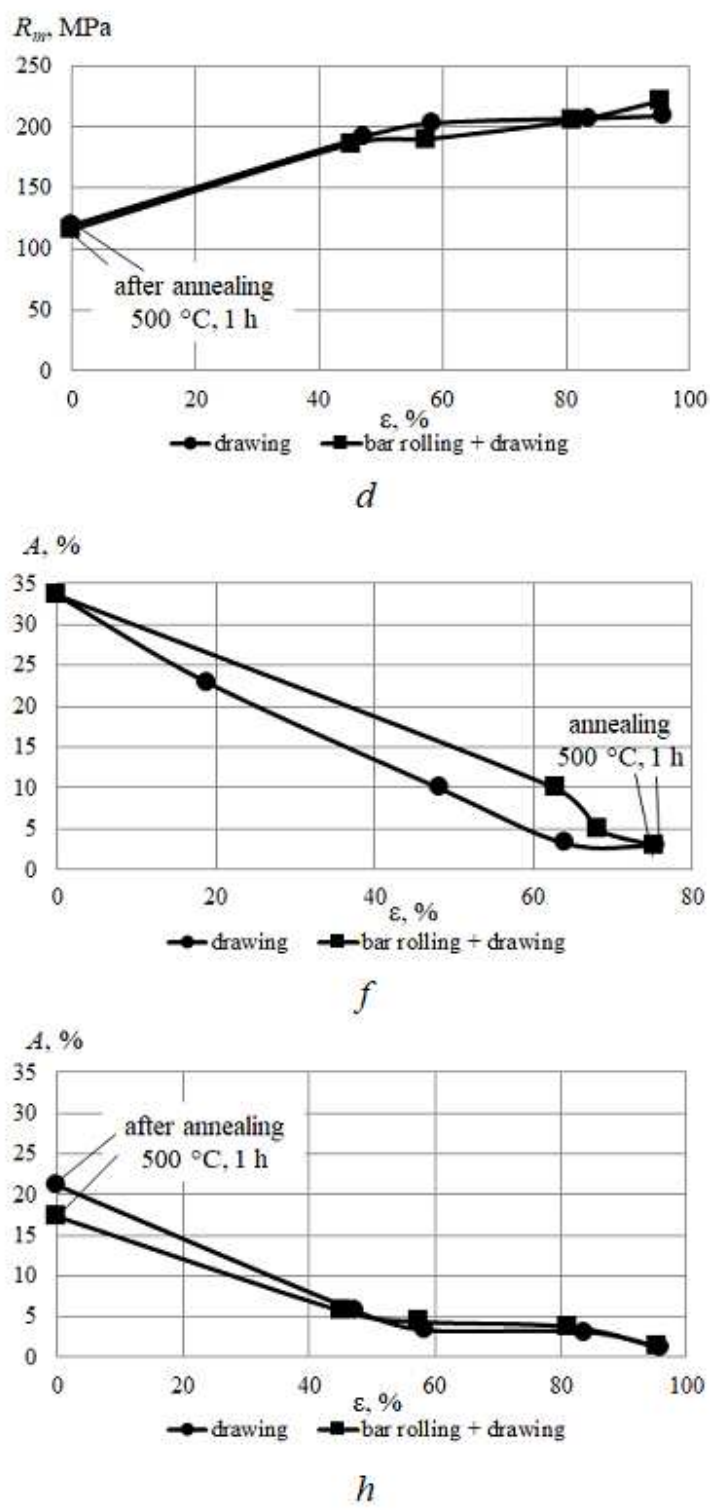

\section{Figure 6}

Mechanical properties of deformed semi-finished products from a test alloy before and after annealing at different roll speeds: a, c, e, g- 4 rpm; b, d, f, h- 8 rpm 


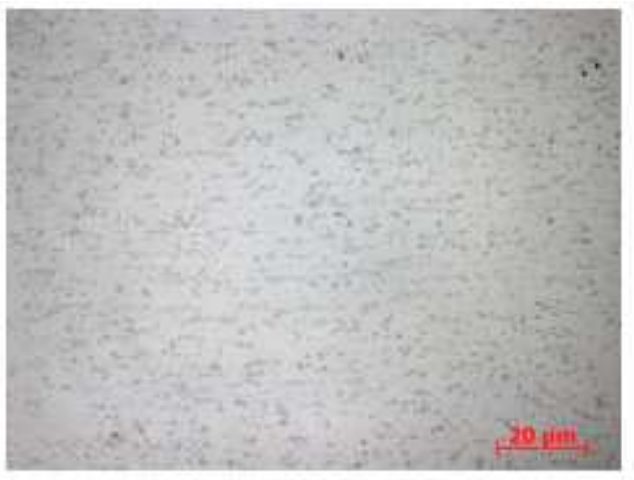

$a$

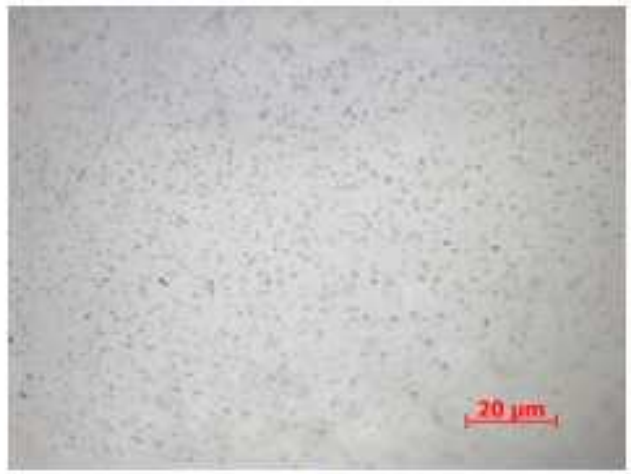

$b$

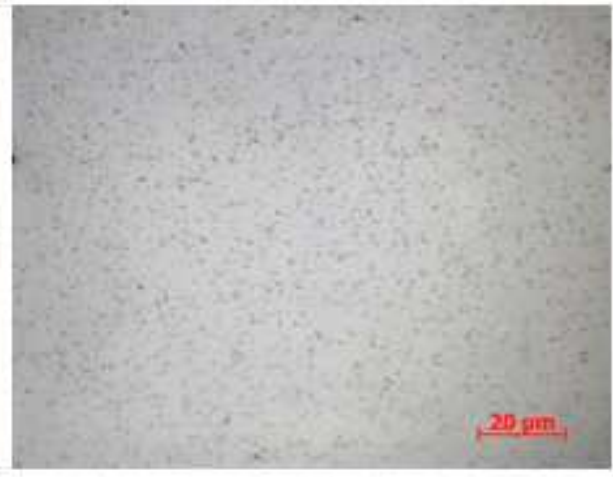

$c$

Figure 7

Microstructure of a rod with a diameter of $5 \mathrm{~mm}$ (a) and a wire made of alloy 01417 with a diameter of $0.5 \mathrm{~mm}$ in deformed (b) and annealed (c) states, $\times 1000$

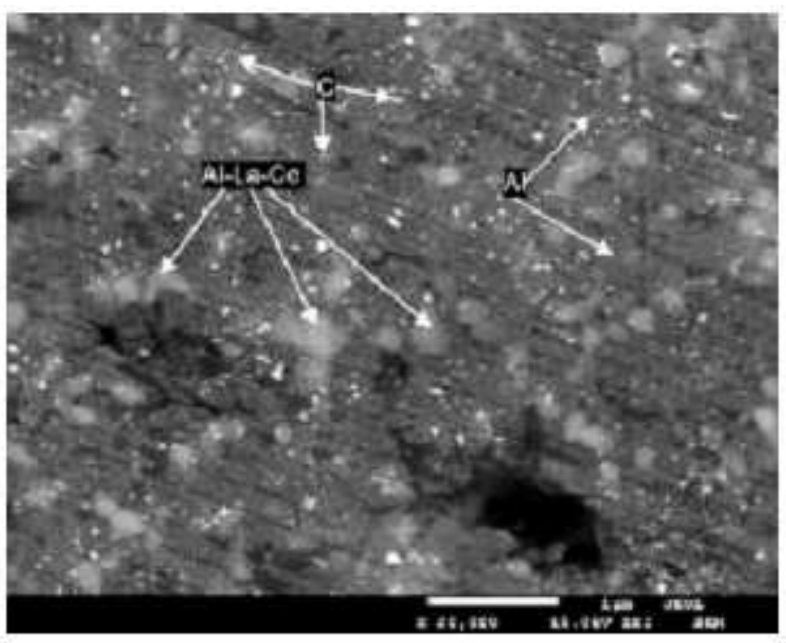

a, $\times 20000$

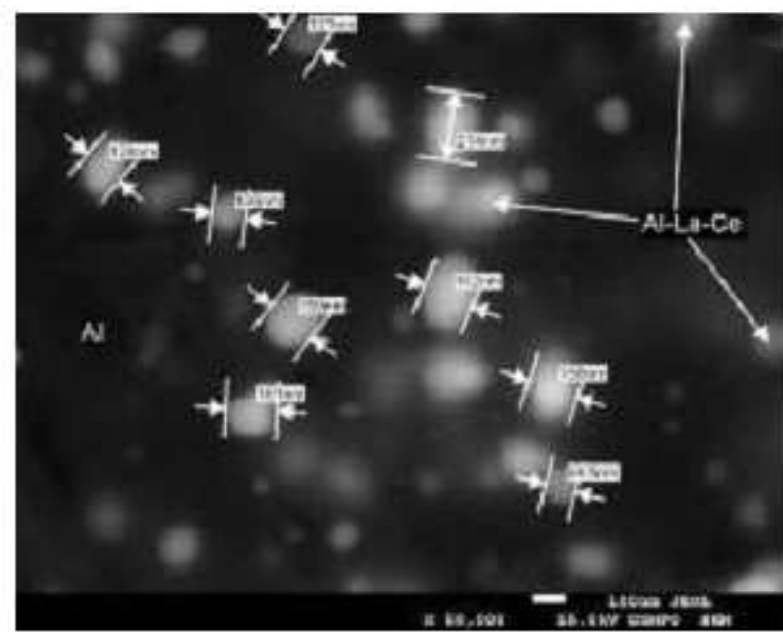

$b, \times 50000$

Figure 8

Microstructure of a wire with a diameter of $0.5 \mathrm{~mm}$ from a test alloy in a cold-deformed state after drawing: $a$ - using SEI contrast, $b$ - using composite contrast COMPO 

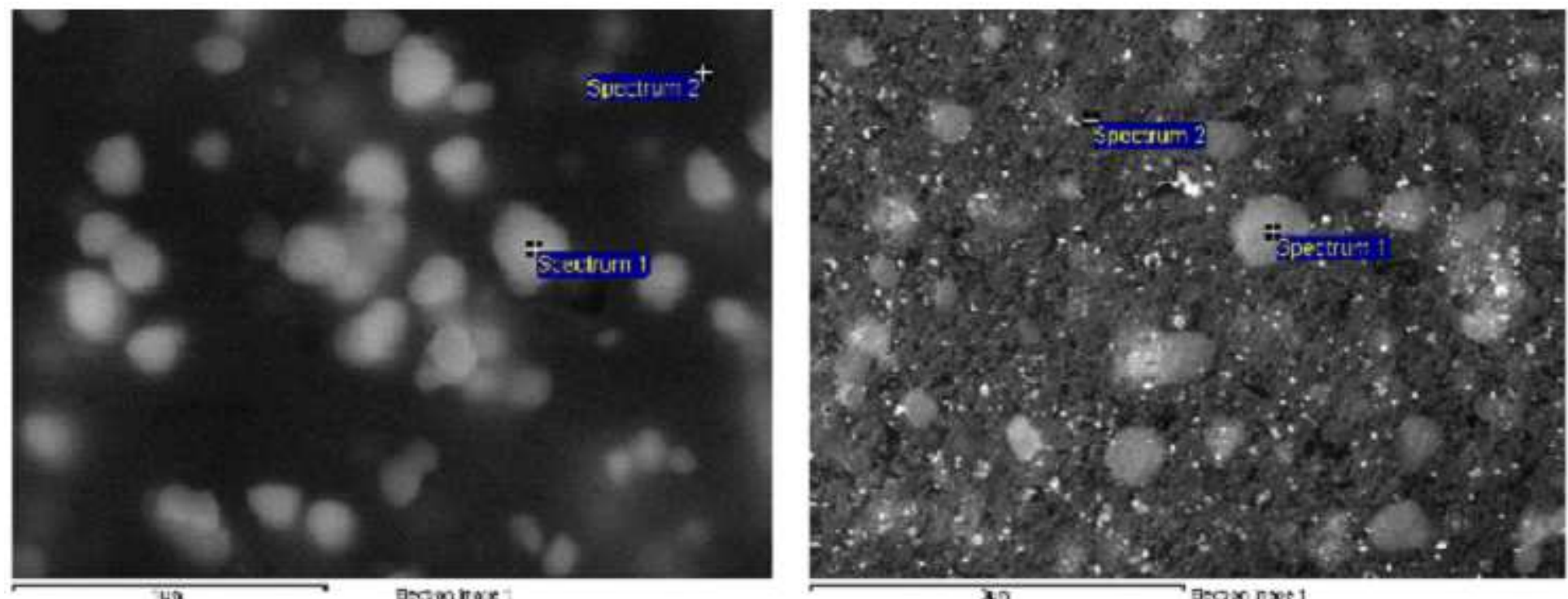

\begin{tabular}{|l|c|c|c|}
\hline \multicolumn{4}{|c|}{ All results in atomic \% } \\
\hline Spectrum & $\mathrm{Al}$ & $\mathrm{La}$ & $\mathrm{Ce}$ \\
\hline Spectrum 1 & 95.56 & 1.61 & 2.83 \\
\hline Spectrum 2 & 99.27 & - & 0.73 \\
\hline
\end{tabular}

$a, \times 20000$

\begin{tabular}{|l|c|c|c|}
\hline \multicolumn{4}{|c|}{ All results in atomic \% } \\
\hline Spectrum & $\mathrm{Al}$ & $\mathrm{La}$ & $\mathrm{Ce}$ \\
\hline Spectrum 1 & 94.25 & 1.88 & 3.87 \\
\hline Spectrum 2 & 99.19 & - & 0.81 \\
\hline \multicolumn{4}{|c|}{$b, \times 50000$} \\
\hline
\end{tabular}

Figure 9

Elemental composition and microstructure of a wire with a diameter of $0.5 \mathrm{~mm}$ from a test alloy in a colddeformed state after drawing: $a$ - using SEl contrast, b - using composite contrast COMPO

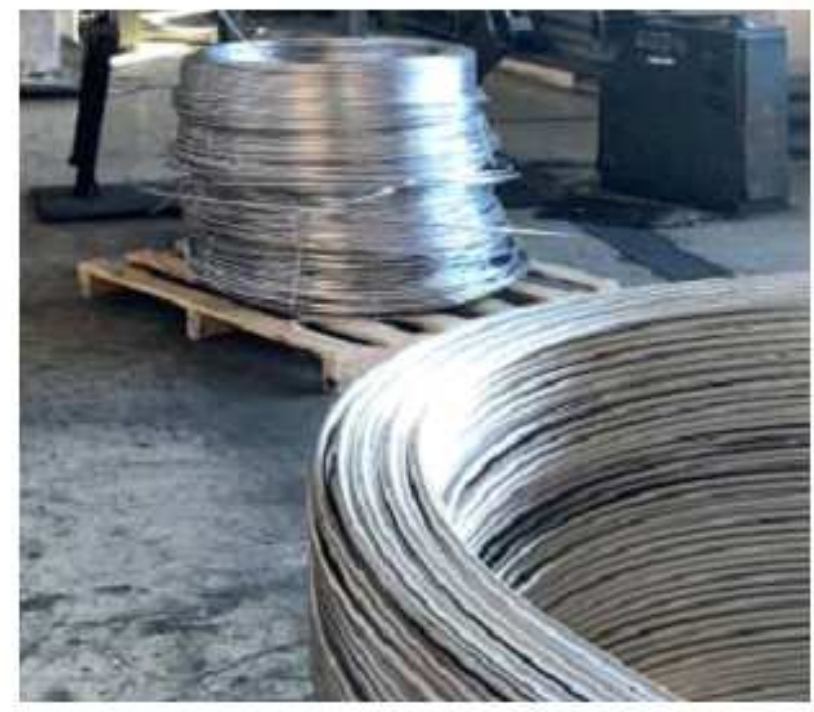

a

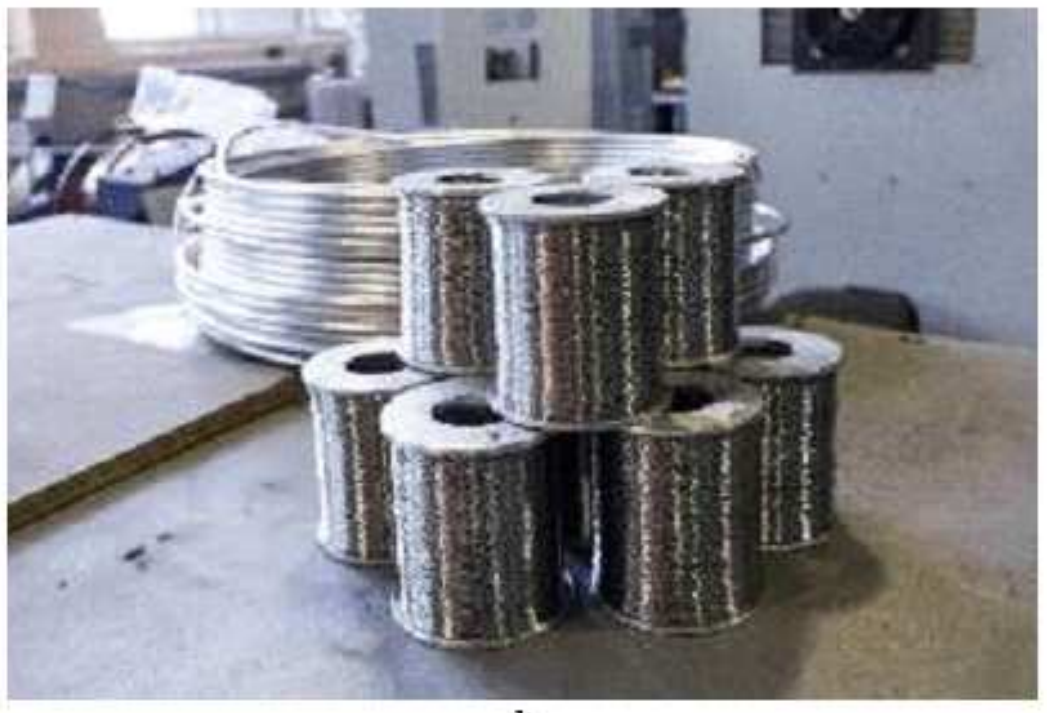

$b$

\section{Figure 10}

Coils of a continuously cast billet (a) from experimental alloy cast by the EMM method and coils with a wire with diameter of $0.5 \mathrm{~mm}$ from this alloy obtained in industrial conditions (b) 